\title{
An aircraft based three channel broadband cavity enhanced absorption spectrometer for simultaneous measurements of $\mathrm{NO}_{3}$, $\mathrm{N}_{2} \mathrm{O}_{5}$ and $\mathrm{NO}_{2}$
}

\author{
O. J. Kennedy ${ }^{1}$, B. Ouyang ${ }^{1}$, J. M. Langridge ${ }^{1, *}$, M. J. S. Daniels ${ }^{3}$, S. Bauguitte ${ }^{2}$, R. Freshwater ${ }^{1}$, M. W. McLeod ${ }^{1}$, \\ C. Ironmonger ${ }^{1}$, J. Sendall ${ }^{1}$, O. Norris ${ }^{1}$, R. Nightingale ${ }^{1}$, S. M. Ball ${ }^{3}$, and R. L. Jones ${ }^{1}$ \\ ${ }^{1}$ Department of Chemistry, University of Cambridge, Cambridgeshire, UK \\ ${ }^{2}$ Facility for Airborne Atmospheric Measurements, Bedfordshire, UK \\ ${ }^{3}$ Department of Chemistry, University of Leicester, Leicestershire, UK \\ *now at: Cooperative institute for Research in Environmental Sciences (CIRES), University of Colorado, \\ Boulder and NOAA Earth System Research Laboratory (ESRL), Chemical Sciences Division, Boulder, CO, USA
}

Received: 17 May 2011 - Published in Atmos. Meas. Tech. Discuss.: 1 June 2011

Revised: 18 August 2011 - Accepted: 24 August 2011 - Published: 7 September 2011

\begin{abstract}
A three channel broadband cavity enhanced absorption spectroscopy (BBCEAS) instrument has been developed for airborne measurements of atmospheric trace gases involved in night-time oxidation chemistry and air quality. The instrument was deployed on board the Facility for Airborne Atmospheric Measurements BAe 146-301 atmospheric research aircraft during the Role of Nighttime Chemistry in Controlling the Oxidising Capacity of the Atmosphere (RONOCO) measurement campaigns between December 2009 and January 2011. In its present configuration (i.e. specifications of the cavity optics and spectrometers) the instrument is designed to measure $\mathrm{NO}_{3}, \mathrm{~N}_{2} \mathrm{O}_{5}$ (by detection of $\mathrm{NO}_{3}$ after thermal dissociation of $\mathrm{N}_{2} \mathrm{O}_{5}$ ), $\mathrm{H}_{2} \mathrm{O}$ and $\mathrm{NO}_{2}$ by characterising the wavelength dependent optical attenuation within ambient samples by molecular absorption around $662 \mathrm{~nm}\left(\mathrm{NO}_{3}\right.$ and $\left.\mathrm{H}_{2} \mathrm{O}\right)$ and $445 \mathrm{~nm}\left(\mathrm{NO}_{2}\right)$. This paper reports novel advancements in BBCEAS instrumentation including a refined method for performing BBCEAS mirror reflectivity calibrations using measurements of the phase delay introduced by the optical cavities to amplitude modulated radiation. Furthermore, a new methodology is introduced for fitting the strong but unresolved transitions of water vapour, which is required for accurate retrieval of water absorption features from the $662 \mathrm{~nm}$ absorption band used to measure $\mathrm{NO}_{3}$ concentrations. The paper also details the first exam-
\end{abstract}

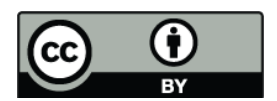

Correspondence to: R. L. Jones (rlj1001@cam.ac.uk) ple of airborne measurements of $\mathrm{NO}_{3}, \mathrm{~N}_{2} \mathrm{O}_{5}$ and $\mathrm{NO}_{2}$ over Europe from a flight over the North Sea and Thames Estuary on the night of the 20 July 2010 , one of the most polluted days of the RONOCO summertime flying period. As part of this analysis, the performance of the BBCEAS instrument is assessed by comparing airborne $\mathrm{NO}_{2}$ measurements to those reported concurrently by a photolytic chemiluminescence based detector.

\section{Introduction}

First reported in the literature by O'Keefe and Deacon (1988), cavity ring-down spectroscopy (CRDS) has become a well-established technique for ultra-sensitive detection of species in the gas and liquid phases (Brown, 2003; Mazurenka et al., 2005; Xu et al., 2002; Wada et al., 2007; Hallock et al., 2002; Scherer et al., 1997; Wang and Zhang, 2000). In particular, it has found frequent application as a detection method for atmospherically important gases, which are often inherently weak absorbers or present in trace quantities (Brown et al., 2002a, b; Simpson, 2003; Wang and Zhang, 2000). More recently, cavity enhanced absorption spectroscopy (CEAS), a related technique first proposed by Engeln et al. (1998), has been demonstrated as a viable alternative to CRDS. CEAS employs continuous wave (CW) light sources instead of the pulsed lasers traditionally used for CRDS. The two techniques achieve similar detection

Published by Copernicus Publications on behalf of the European Geosciences Union. 
performance, although CEAS is often implemented using simpler experimental schemes that do not require the fast response detectors needed for CRDS. A popular variant of CEAS, and that used in the present work, is broadband cavity enhanced absorption spectroscopy (BBCEAS) which was first reported in the literature by Fiedler et al. (2003). BBCEAS differs from single wavelength CEAS in that it captures wavelength resolved absorption spectra, which can be used to simultaneously and unambiguously quantify multiple absorbing species in a sample through the application of spectral fitting methods commonly used for differential optical absorption spectroscopy (Platt and Stutz, 2008; Ball et al. 2004; Ball and Jones, 2009). To date BBCEAS has been used in a diverse range of laboratory investigations. Examples include: Langridge et al. (2009) who simultaneously monitored $\mathrm{HONO}$ and $\mathrm{NO}_{2}$ concentrations while studying the photocatalytic properties of a $\mathrm{TiO}_{2}$ doped glass surface; Chen and Venables (2011) who determined the absorption cross sections of $\mathrm{O}_{3}, \mathrm{O}_{4}, \mathrm{SO}_{2}$ and various hydrocarbons in the near-ultraviolet wavelength region; and Ball et al. (2010) who simultaneously monitored $\mathrm{I}_{2}, \mathrm{O}_{4}$ and $\mathrm{H}_{2} \mathrm{O}$ concentrations during an investigation of biogenic emissions by a range of seaweeds. BBCEAS has also been utilised, albeit to a lesser extent, for in situ atmospheric field measurements. These studies have most commonly involved observations of $\mathrm{NO}_{3}$ via its strong $B^{2} E^{\prime}-X^{2} A_{2}^{\prime}$ electronic transition centred around $662 \mathrm{~nm}$, and its reservoir species $\mathrm{N}_{2} \mathrm{O}_{5}$, which is measured indirectly following thermal dissociation to $\mathrm{NO}_{3}$. For example, BBCEAS was used by Langridge et al. (2008) and later by Benton et al. (2010), respectively, to measure the sum of $\mathrm{NO}_{3}$ and $\mathrm{N}_{2} \mathrm{O}_{5}$ in the marine boundary layer at Roscoff, France and in and above the urban boundary layer in London by deploying a BBCEAS instruments at the top of the BT communications tower. The purpose of this paper is to present what is to the authors' knowledge the first aircraft-based BBCEAS instrument for in situ atmospheric measurements. It has three channels and is capable of simultaneously measuring concentrations of $\mathrm{N}_{2} \mathrm{O}_{5}, \mathrm{NO}_{3}$, $\mathrm{H}_{2} \mathrm{O}$ and $\mathrm{NO}_{2}$. These gases are of interest due to their participation in a range of atmospheric processes: oxidation by $\mathrm{NO}_{3}$ controls the lifetimes of some species, including a number of volatile organic compounds (VOCs) that are important for photochemical ozone production, while deposition of $\mathrm{N}_{2} \mathrm{O}_{5}$ onto certain aerosol surfaces represents a potentially important but presently unquantified sink of diurnally aggregated $\mathrm{NO}_{\mathrm{x}}$ (Chang et al., 2011). The BBCEAS instrument is one of a suite of instruments on board the United Kingdom's BAe 146-301 Facility for Airborne Atmospheric Measurements (FAAM) research aircraft, which collectively provide comprehensive characterisation of a range of important trace gases and aerosol species (Pfister et al., 2006; Capes et al., 2009; Johnson et al., 2009; Lewis et al., 2007; AndrésHernández et al., 2010).

\section{BBCEAS experimental technique}

The BBCEAS technique and spectral analysis procedure has been widely reported in the literature and are only briefly described here. For further details the reader is directed to recent publications by Langridge et al. (2008), Varma et al. (2009) and Thalmann et al. (2010) (the latter two include a detailed discussion on the retrieval of aerosol extinction from BBCEAS absorption spectra). A BBCEAS experiment involves irradiation of a high finesse optical cavity, formed using two highly reflective mirrors, by an incoherent broadband $\mathrm{CW}$ light source. Under irradiation, photons resonate between the cavity mirrors increasing their average lifetime within the cavity by a factor of $1 /[1-R(\lambda)]$, where $R(\lambda)$ is the wavelength dependent reflectivity of the cavity's mirrors. For a typical BBCEAS cavity of $1 \mathrm{~m}$ length constructed from $R(\lambda)=0.9999$ mirrors, the average $1 / e$ lifetime of intracavity photons is $30 \mu \mathrm{s}$. In this time, photons traverse an effective path length of 10 kilometres inside the cavity, making possible observations of optical extinctions of the order of $1 \times 10^{-9} \mathrm{~cm}^{-1}$. The intensity transmitted by an optical cavity under $\mathrm{CW}$ irradiation rapidly reaches steady state. The steady state intensity is determined by the balance between the rate at which light couples into the cavity and the rate at which it exits it due to transmission through the cavity mirrors and extinction (equal to the sum of absorption and scattering) by the intracavity medium. Engeln et al. (1998) demonstrated that with accurate knowledge of cavity mirror reflectivities, the steady state intensities measured in the presence and absence of an intracavity optical attenuator can be used to infer the magnitude of intracavity photon extinction using:

$\alpha(\lambda)=\left(\frac{I_{0}(\lambda)}{I(\lambda)}-1\right)\left(\frac{1-R(\lambda)}{d}\right)$

where: $d$ is the distance separating the cavity mirrors and, at wavelength $\lambda, \alpha(\lambda)$ is the optical extinction coefficient of the sample within the cavity and $I(\lambda)$ and $I_{0}(\lambda)$ are the transmitted intensities in the presence and absence of the absorber respectively. An important feature of BBCEAS is that the concentrations of the target molecules can be retrieved from the wavelength resolved extinction coefficient by spectrally isolating the more highly structured molecular absorption from the smoothly varying extinction due to Rayleigh and Mei scattering. In practise, the procedure involves using a least squares algorithm to simultaneously fit the target molecules' absorption cross sections together with a quadratic or cubic polynomial to the measured extinction coefficient. Note that in order to limit changes in the measured extinction coefficient due to variations in lamp intensity, which determines the number of photons coupled into the cavity, it is normally required that measurements of $I_{0}(\lambda)$ be re-acquired periodically during BBCEAS experiments (details of how $I_{0}(\lambda)$ is acquired in the present instrument are given in Sect. 3.3). 


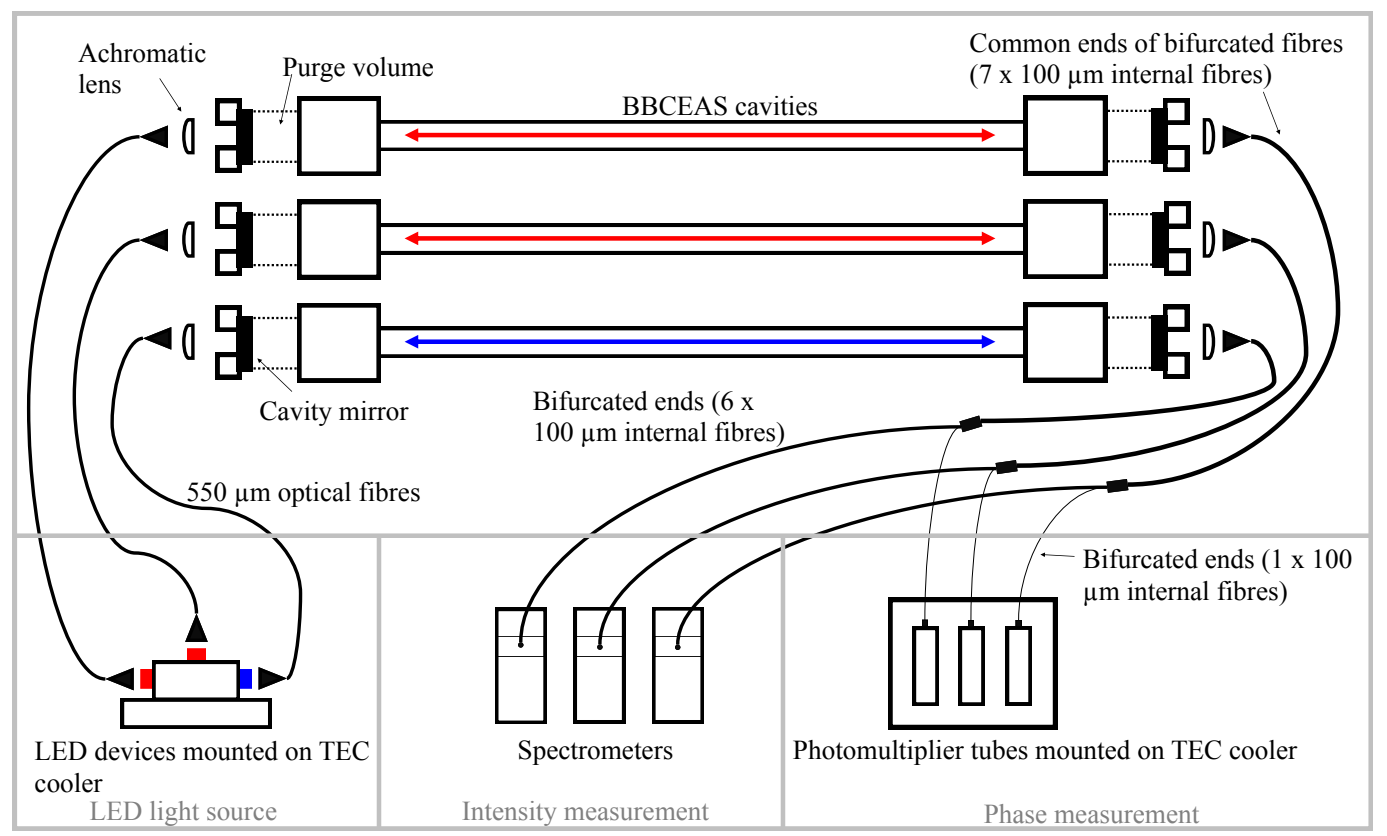

Fig. 1. The optical layout of the three channel broadband cavity enhanced absorption spectrometer.

Table 1. Optical setup and spectral performance of each spectrometer used in the BBCEAS instrument.

\begin{tabular}{llllll}
\hline & $\begin{array}{l}\text { Species } \\
\text { measured }\end{array}$ & $\begin{array}{l}\text { Entrance slit } \\
\text { width }(\mu \mathrm{m})\end{array}$ & $\begin{array}{l}\text { Groove density of } \\
\text { diffraction grating } \\
\left(\mathrm{mm}^{-1}\right)\end{array}$ & $\begin{array}{l}\text { Wavelength } \\
\text { coverage } \\
(\mathrm{nm})\end{array}$ & $\begin{array}{l}\text { Spectral } \\
\text { resolution } \\
\text { FWHM }(\mathrm{nm})\end{array}$ \\
\hline Channel 1 & $\mathrm{N}_{2} \mathrm{O}_{5}+\mathrm{NO}_{3}$ & 100 & 1200 & $615-706$ & 0.9 \\
Channel 2 & $\mathrm{NO}_{3}$ & 200 & 2400 & $639-680$ & 0.75 \\
Channel 3 & $\mathrm{NO}_{2}$ & 100 & 2400 & $410-482$ & 0.4 \\
\hline
\end{tabular}

\section{Instrument description}

\subsection{Optical layout}

The optical layout of the three channel instrument is detailed schematically in Fig. 1. The instrument comprises three $94 \mathrm{~cm}$ long optical cavities each constructed from pairs of high reflectivity mirrors. Each mirror is isolated from the sample flow by a purge volume that is continuously flushed with 100 standard cubic centimetres per minute (SCCM) of dry nitrogen to prevent degradation of reflectivity by deposition of aerosols and precipitation to the mirror surfaces during flights. Two of the optical cavities (those for $\mathrm{NO}_{3}$ and $\mathrm{N}_{2} \mathrm{O}_{5}$ detection), herein referred to as channels 1 and 2 , are identical from an optical standpoint and employ mirrors with maximum reflectivity of 0.9999 centred at $650 \mathrm{~nm}$ and have radii of curvature of $6 \mathrm{~m}$ (Layertec $\mathrm{GmbH}$, Germany). Channels 1 and 2 are excited by red light emitting diodes (LedEngin LZ1-10R205) that consume 4.7 W of electrical power. At full luminosity each LED outputs $685 \mathrm{~mW}$ of optical power and has an approximately Gaussian shaped emission of approximately $25 \mathrm{~nm}$ full width at half maximum (FWHM) centred at $660 \mathrm{~nm}$. The third cavity (for detection of $\mathrm{NO}_{2}$ ), herein referred to as channel 3, uses mirrors with peak reflectivities of 0.99985 at $445 \mathrm{~nm}$ and radii of curvature of $6 \mathrm{~m}$ (Layertec GmbH, Germany). The corresponding light source is a dental blue LED (LedEngin LZ1-10DB05) which consumes of $5.7 \mathrm{~W}$ of electrical power and outputs $1175 \mathrm{~mW}$ of optical power with a near-Gaussian emission profile of $25 \mathrm{~nm}$ FWHM centred around $460 \mathrm{~nm}$.

Light emerging from each of the LEDs is spatially incoherent, and collimation is therefore required for effective coupling into the corresponding optical channel. This is achieved by first coupling the LED outputs into multi-mode optical fibres with $550 \mu \mathrm{m}$ diameter cores and 0.22 numerical apertures. The output of each fibre is then re-collimated using an achromatic lens with a $5 \mathrm{~cm}$ focal length. Note that the use of fibre optics conveniently allows the LEDs to be mounted on a single thermo-electric cooler (TEC) inside an enclosure for temperature regulation. 


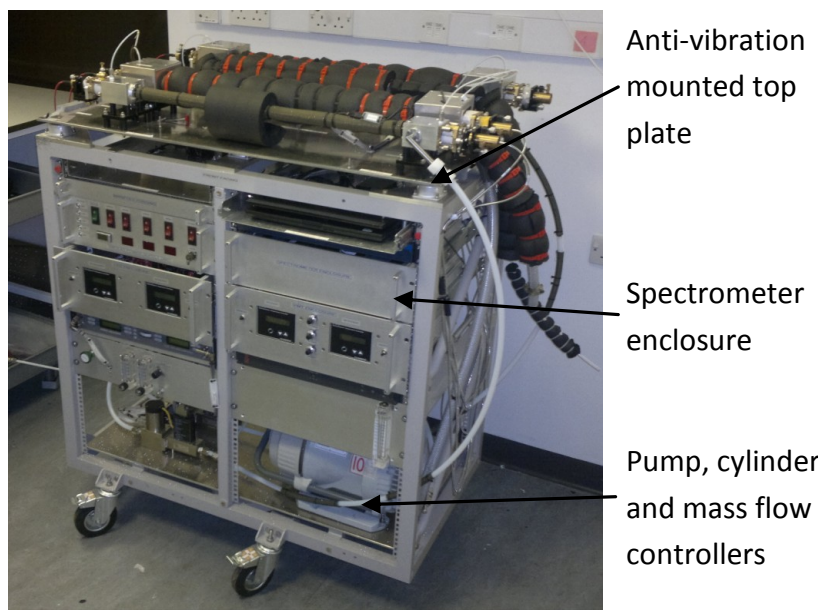

Fig. 2. A photograph of the three channel LED based BBCEAS instrument for use on board the UK BAe 146-301 research aircraft.

Light transmitted through each optical channel is coupled into a bifurcated fibre optic bundle using a $30 \mathrm{~mm}$ focal length achromatic lens. The common end of each bifurcated fibre bundle houses seven $100 \mu \mathrm{m}$ diameter, $0.22 \mathrm{nu}$ merical aperture multi-mode fibres. Six of these fibres are directed to a miniature Ocean Optics QE65000 spectrometer, which measures the wavelength dependent cavity output intensity. The remaining fibre is directed to a photomultiplier tube (PMT) that is used for the phase sensitive measurements needed to quantify the cavity mirror reflectivity (see Sect. 3.3). In total three spectrometers are used, each comprising a spectrograph interfaced to a charged couple device (CCD) that is thermally stabilised at $-15^{\circ} \mathrm{C}$ to minimise dark current. The diffraction gratings and entrance slits used for each spectrometer were chosen to achieve the desired spectral coverage and resolution for the three channels, as detailed in Table 1.

To overcome the effects of vibrations, especially those associated with take-off and landing, the optical components are decoupled from the instrument frame and aircraft chassis. Each of the three cavities is mounted on a $6 \mathrm{~mm}$ thick aluminium plate (see Fig. 2) which is attached to the top of the instrument frame using anti-vibration (AV) mounts. In a similar fashion, the three spectrometers are attached to another AV mounted aluminium plate which is positioned inside a darkened enclosure (also visible in Fig. 2).

\subsection{Ambient air sampling and inlet design}

A schematic illustrating the flow of ambient air through the instrument is shown in blue in Fig. 3. The same figure also shows the flows of nitrogen flush gas (red) used periodically when acquiring the background spectrum of light transmitted through the cavity in the absence of the ambient absorbers - see Sect. 3.3. The instrument has two inlets situated on the aircraft fuselage at approximately $4 \mathrm{~m}$ from the aircraft nose and $10 \mathrm{~cm}$ from the aircraft body (i.e. to sample air from beyond the aircraft's boundary layer), as shown in Fig. 4. Both inlets are rear facing to prevent entry of precipitation. The first inlet, inlet 1 , is used for sampling ambient air while the second inlet, inlet 2 , is used to draw ambient air through a sheath encompassing channel 2 (see Table 1), which measures ambient $\mathrm{NO}_{3}$ concentrations. The sheath flow maintains the temperature of channel 2 (the temperatures of the cavities are measured using PT1000 temperature sensors equally spaced along the cavity tubes) at ambient temperature. This minimises the potential for perturbation of the $\mathrm{N}_{2} \mathrm{O}_{5} / \mathrm{NO}_{3}$ equilibrium due to heating of the sample as it enters the aircraft cabin. Note that the pressure inside the cavities is inferred from pressure sensors at the exhausts of conduits 1 and 2. During testing, the readings from these sensors were in excellent agreement with those reported by a pressure gauge when attached to $1 / 8$ inch fittings on each of the instruments mirror mounts (i.e. those normally attached to the lines which bring the nitrogen gas used to purge the volume directly in front of each mirror face - see Sect. 3.1).

During sampling ambient air is drawn through inlet 1 , which consists of a thermally insulated $60 \mathrm{~cm}$ long $5 / 32 \mathrm{inch}$ internal diameter (ID) perfluoroalkoxy (PFA) tube, at a rate of 501 per minute (LPM) (a volumetric flow is used to maintain a constant sample residence time). A PFA tee-piece is then used to divide the flow into two conduits, herein referred to as conduits 1 and 2, which pull 30 LPM and 20 LPM respectively. The purpose of such large flow rates is to minimise the sample residence time of each channel and thus to reduce the wall losses of $\mathrm{N}_{2} \mathrm{O}_{5}$ and $\mathrm{NO}_{3}$, as is described in more detail in Sect. 4. In conduit 1, the sample is first directed through a preheater consisting of a $68 \mathrm{~cm}$ long $1 / 2$ inch outside diameter (OD) PFA tube which is heated to $120^{\circ} \mathrm{C}$ to facilitate the complete thermal dissociation of $\mathrm{N}_{2} \mathrm{O}_{5}$ in the sample into $\mathrm{NO}_{3}$ and $\mathrm{NO}_{2}$. A modelling study simulating the flow conditions (i.e. flow rates, flow line geometries etc.) gave dissociation efficiencies of $\mathrm{N}_{2} \mathrm{O}_{5}$ greater than $99.6 \%$ for a range of inlet air temperatures $(-20$ to $20^{\circ} \mathrm{C}$ ) and $\mathrm{NO}_{2}$ concentrations ( 2 to $\left.60 \mathrm{ppb}\right)$. The expectation is that the efficiency is therefore sufficiently close to unity c.f. other sources of error (as is detailed in Sect. 4) that $100 \%$ conversion efficiency is assumed. The heated sample then enters channel 1, comprised of a 7/8 inch ID PFA tube maintained at $80^{\circ} \mathrm{C}$, where the sum of the concentrations of ambient $\mathrm{NO}_{3}$ and $\mathrm{NO}_{3}$ formed from thermally dissociated $\mathrm{N}_{2} \mathrm{O}_{5}$ is measured. In conduit 2, the sample passes via an $8 \mathrm{~cm}$ long 5/32 inch ID PFA tube into channel 2, comprised of a $1 / 2$ inch ID PFA tube, where detection of ambient $\mathrm{NO}_{3}$ occurs. The flow exiting channel 2 is immediately directed into channel 3, comprised of a 7/8 inch ID PFA tube, where $\mathrm{NO}_{2}$ detection occurs. The gas outflows from conduits 1 and 2 are recombined and pass through a flow controller and pump before entering the aircraft exhaust line. 


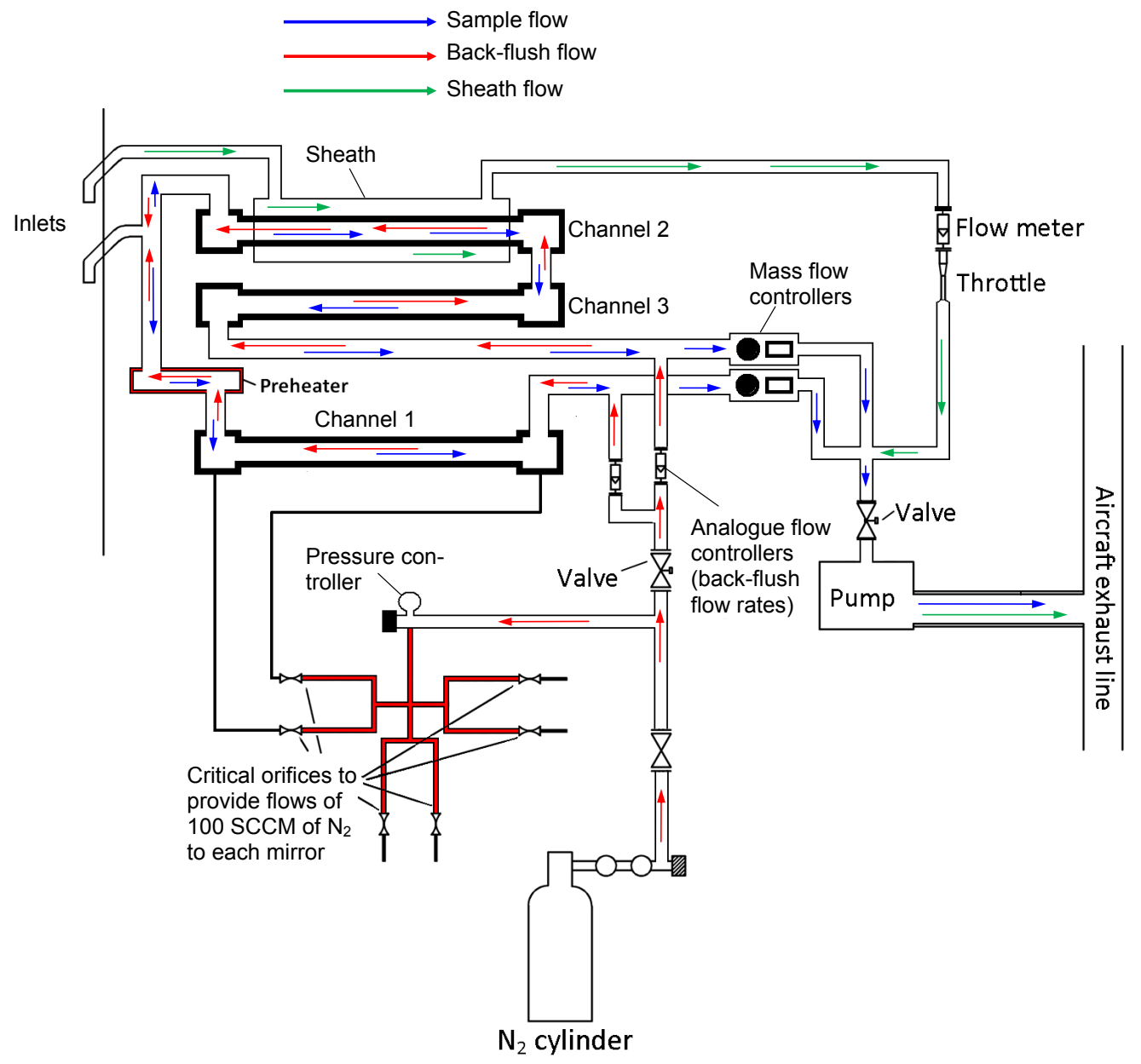

Fig. 3. A schematic showing air flow through the instrument: ambient air (blue) and nitrogen (red) used for background acquisition and flushing of the mirror purge volumes.

\subsection{Acquisition of $I_{0}(\lambda)$ and determination of cavity mirror reflectivities}

During flight operations, the background spectrum $I_{0}(\lambda)$ (i.e. that of light transmitted through the cavity when purged with nitrogen), is measured on the ground before sampling begins and half-hourly in-flight thereafter to account for potential lamp intensity variations. Measurements are performed by stopping the flow of ambient air through the instrument and instead back-flowing nitrogen from a cylinder at 5 standard 1 per minute (SLPM) through conduits 1 and 2 and out of the sampling inlet (flows shown in red in Fig. 3). Before measurements of $I_{0}(\lambda)$ are taken, a period of $20 \mathrm{~s}$ is allowed to elapse to ensure complete purging of the cavities.

Knowledge of the wavelength dependent mirror reflectivity is an additional quantity required for quantitative absorption measurements using BBCEAS, in accordance with Eq. (1). In the present instrument, this quantity is determined by measuring the phase-shift introduced to amplitude modulated radiation by the optical cavities, a method that has been used previously with some success (Langridge et al., 2008). The technique relies on the proportionality between the phase delay introduced by the cavity and the lifetime of photons within it, given by:

$\tan \phi(\lambda)=-\Omega \tau(\lambda)$

where: $\phi(\lambda)$ is the phase delay, $\Omega$ is the angular frequency of the phase modulation and $\tau(\lambda)$ is the ringdown time which is equivalent to the $1 / \mathrm{e}$ intracavity photon lifetime. Given knowledge of the cavity ringdown time, the mirror reflectivity is calculated using:

$R(\lambda)=1-d\left(\frac{1}{c \tau(\lambda)}-\alpha(\lambda)\right)$

where: $d$ is the cavity length, $c$ is the speed of light and, in the present case, $\alpha(\lambda)$ is the wavelength dependent extinction coefficient of Rayleigh scattering in nitrogen.

The experimental complexity and time required for phaseshift measurements has been greatly reduced in the current 
instrument with respect to previous implementations (Benton et al., 2010; Langridge et al., 2008). The principal change is to replace the monochromator previously used to scan through the range of measurement wavelengths with an interference filter of $5 \mathrm{~nm}$ FWHM bandwidth. The centre wavelength of the filter is chosen for each cavity so that the peak mirror reflectivity is measured. The mirror reflectivity across the full measurement bandwidth is then determined by linearly scaling the reference mirror reflectivity profiles, measured previously in the laboratory using a calibration gas (Langridge et al., 2006), to the value of $R$ measured in the interference filter's bandpass. During flights, reflectivity measurements are conducted immediately after determination of $I_{0}$ (see earlier in this section) when the cavity is purged with nitrogen. The modulation required for the measurements is introduced into the light sources only temporarily while determination of the phase delay takes place. When used during the RONOCO campaign, this method gave excellent agreement between $\mathrm{NO}_{2}$ concentrations observed in channel 3 and values reported by a chemiluminescence detector. Further details of an example in situ comparison of these two $\mathrm{NO}_{2}$ measurement techniques are presented in the results section (Sect. 5.3).

\section{$4 \mathrm{NO}_{3}$ and $\mathrm{N}_{2} \mathrm{O}_{5}$ measurement accuracy}

Earlier work by Dubé et al. (2006), Fuchs et al. (2008) and Wagner et al. (2011) highlighted the difficulties in measuring the concentrations of atmospheric $\mathrm{NO}_{3}$ and $\mathrm{N}_{2} \mathrm{O}_{5}$ (after thermal dissociation) using cavity-based absorption methods. In the current BBCEAS instrument, therefore, certain correction factors are applied to measurements in channel 1 (sum of ambient and dissociated $\mathrm{NO}_{3}$ ) and channel 2 (ambient $\mathrm{NO}_{3}$ ) to account for wall losses of ambient $\mathrm{NO}_{3}$, inaccuracies in the temperature and pressure dependent absorption cross sections which are used to infer $\mathrm{NO}_{3}$ and $\mathrm{H}_{2} \mathrm{O}$ concentrations, and uncertainties in the length of the cavity occupied by the sample (due to gas exchange between the main part of the cavity and the nitrogen purge regions immediately in front of the mirrors). There is also an additional correction factor applied specifically to measurements channel 1 to account for wall losses of $\mathrm{N}_{2} \mathrm{O}_{5}$ in the inlet and wall losses of thermally dissociated $\mathrm{NO}_{3}$ in the preheater and detection cell. Each of these correction factors, along with the associated uncertainties, are considered in detail in the following sections.

\subsection{Determination of wall losses}

\subsubsection{The equilibrated source of $\mathrm{NO}_{3}$ and $\mathrm{N}_{2} \mathrm{O}_{5}$}

For determination of the wall losses of $\mathrm{NO}_{3}$ and $\mathrm{N}_{2} \mathrm{O}_{5}$, a calibration procedure was developed in which the BBCEAS instrument was supplied with an equilibrated mixture of $\mathrm{NO}_{3}$ and $\mathrm{N}_{2} \mathrm{O}_{5}$ from a calibration source. This source contained a sample of crystalline $\mathrm{N}_{2} \mathrm{O}_{5}$, stabilised between temperatures

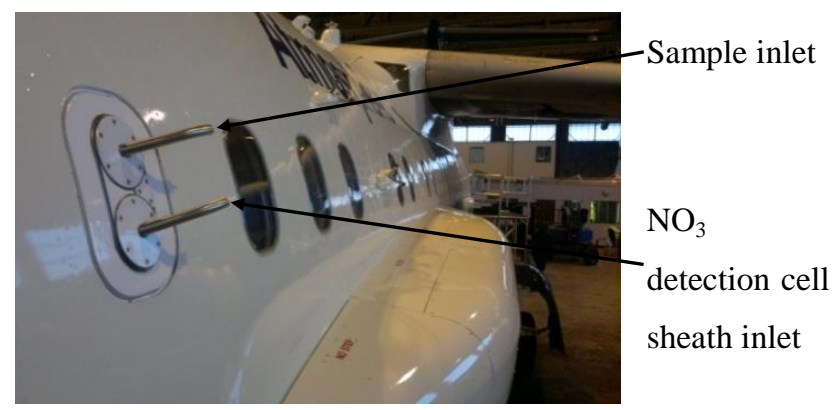

Fig. 4. Position of the BBCEAS instrument's inlets on the fuselage of the FAAM BAe 146-301 aircraft.

of -80 and $-77{ }^{\circ} \mathrm{C}$ with a TEC linked to a dry ice/methanol bath (based on a design used by Fuchs et al., 2008). A flow of nitrogen (10 to 400 SCCM) passed over the crystalline $\mathrm{N}_{2} \mathrm{O}_{5}$, and was further diluted by a second nitrogen flow $(0$ to 5 SLPM). A combination of the temperature set-point and the ratio of the nitrogen flows was used to supply the aircraft BBCEAS instrument with calibration samples containing atmospherically relevant $\mathrm{N}_{2} \mathrm{O}_{5}$ concentrations between $100 \mathrm{ppt}$ and $2 \mathrm{ppb}$. The calibration source additionally has its own heated LED-BBCEAS cavity to monitor the source's stability and hence the total $\left[\mathrm{N}_{2} \mathrm{O}_{5}+\mathrm{NO}_{3}\right]$ supplied to the aircraft instrument. Prior to sampling into the BBCEAS instrument, the diluted mixture passed through a 101 glass vessel downstream of the source (mean residence time $=20 \mathrm{~s}$ ) in order to ensure that $\mathrm{N}_{2} \mathrm{O}_{5}$ entrained into the gas flow had reached chemical equilibrium with $\mathrm{NO}_{3}$. The requirement for the equilibration of the sample mixture is detailed in Sect. 4.1.3, in which direct wall losses of $\mathrm{N}_{2} \mathrm{O}_{5}$ are determined.

\subsubsection{Determination of wall losses of ambient $\mathrm{NO}_{3}$ in channels 1 and 2}

This section details the determination of the transmission efficiencies of ambient $\mathrm{NO}_{3}$ (i.e. the proportion of ambient $\mathrm{NO}_{3}$ that reaches the middle of the detection cells) into channels 1 and 2 (see Table 1), herein referred to as $T_{1}$ and $T_{2}$ respectively. $T_{1}$ and $T_{2}$ were calculated by experimentally deriving the pseudo first order rate constant for the reaction between $\mathrm{NO}_{3}$ and the instrument's internal surface, $k_{\mathrm{NO}_{3} \text { loss, }}$, as described by reaction $\mathrm{R} 1$.

$\mathrm{NO}_{3} \rightarrow$ walls $\quad k_{\mathrm{NO}_{3} \text { loss }}$

Two materials were initially considered for use in constructing the cavity tubes, which are in contact with the ambient samples: titanium coated with PTFE, chosen for its rigidity and thermal properties, and PFA, well known for its chemical inertness. The first order loss coefficient of $\mathrm{NO}_{3}$ to each of these materials was determined in laboratory experiments during the construction phase of the instrument. These experiments involved sampling the equilibrated $\mathrm{NO}_{3} / \mathrm{N}_{2} \mathrm{O}_{5}$ 


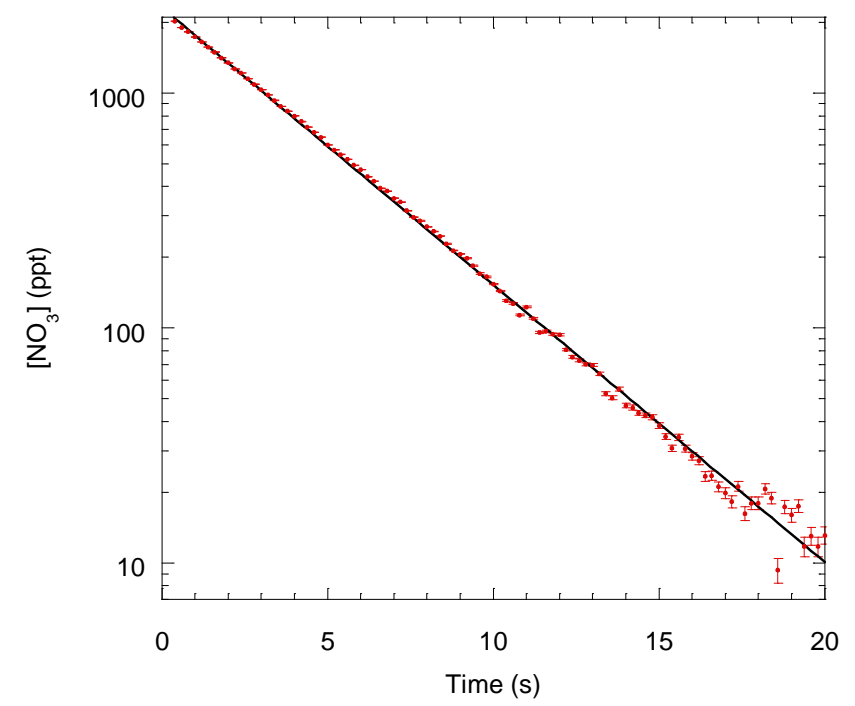

Fig. 5. Observed (red) and fitted (black) decay of $\mathrm{NO}_{3}$ inside the BBCEAS instrument's heated PFA detection cell (channel 1). The measured decay time constant for $\mathrm{NO}_{3}$ wall loss is $0.27 \mathrm{~s}^{-1} \pm$ $0.02 \mathrm{~s}^{-1}$, which for the flow conditions of the BBCAES instrument corresponds to a transmission efficiency for ambient $\mathrm{NO}_{3}$ into channels 1 and 2 of $90 \%$ and $96 \%$ respectively.

mixture from the calibration source into channel 1 (sampling conditions described in Sect. 3.2). When the observed intracavity concentration of $\mathrm{NO}_{3}$ reached a steady state, the flow of the calibration sample was rapidly stopped by closing the valve on the exhaust line to the BBCEAS instrument's pump. The rate of loss of $\mathrm{NO}_{3}$ to the walls of channel 1 was characterised by fitting an exponential function to the observed first order decay of intracavity $\mathrm{NO}_{3}$ (an example is shown in Fig. 5 for the PFA cell). These experiments were performed using channel 1 in order to eliminate the effects of repartitioning of the equilibrium between $\mathrm{NO}_{3}$ and $\mathrm{N}_{2} \mathrm{O}_{5}$ as $\mathrm{NO}_{3}$ is lost to the internal surfaces of cavity. As mentioned in Sect. 3.2, channel 1 is heated to prevent reformation of $\mathrm{N}_{2} \mathrm{O}_{5}$, after complete thermal dissociation in the preheater, through the reaction between $\mathrm{NO}_{3}$ and $\mathrm{NO}_{2}$. Therefore the $k_{\mathrm{NO}_{3} \text { loss }}$ measured at high temperature represents an upper limit for the loss of $\mathrm{NO}_{3}$ to the instrument walls in both channels 1 and 2 .

The first order uptake coefficient of $\mathrm{NO}_{3}$ to PFA, shown in Fig. 5, was found to be $0.27 \mathrm{~s}^{-1} \pm 0.02 \mathrm{~s}^{-1}$, which is in good agreement with that measured by Crowley et al. (2010) $\left(0.25 \mathrm{~s}^{-1}\right)$. The uptake coefficient of $\mathrm{NO}_{3}$ to PTFE coated titanium was found to be $0.8 \mathrm{~s}^{-1} \pm 0.02 \mathrm{~s}^{-1}$, indicating much faster diffusion controlled wall losses. Given these results, final construction of the instrument utilised PFA for all wetted parts in order to minimise $\mathrm{NO}_{3}$ losses. Based on the calculated residence times for channels $1(380 \mathrm{~ms})$ and $2(170 \mathrm{~ms})$, $T_{1}$ and $T_{2}$ are $90 \%$ and $96 \%$ respectively. However, due to the accuracy of $k_{\mathrm{NO}_{3} \text { loss }}$, the uncertainties associated with $T_{1}$

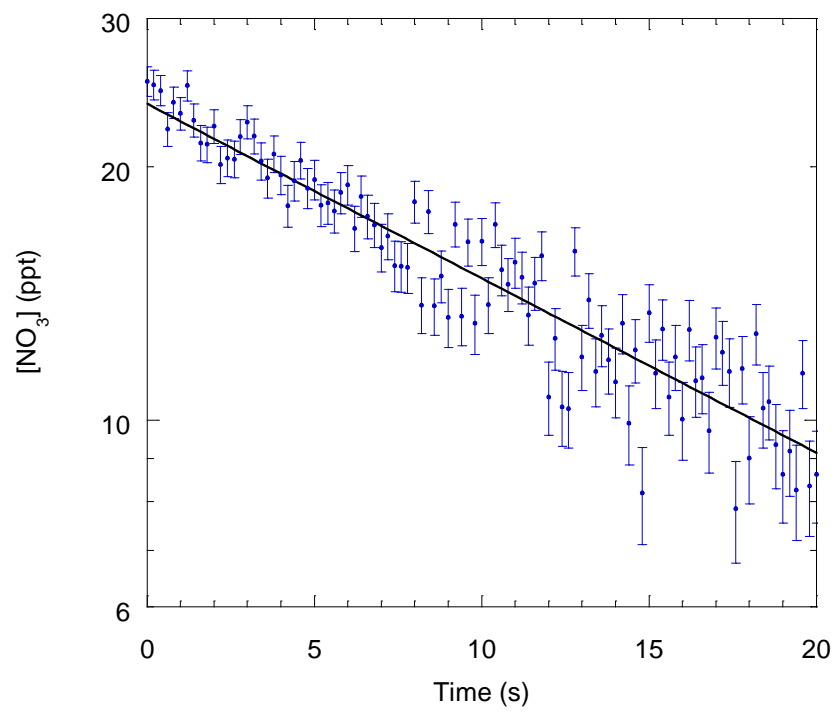

Fig. 6. Decay of $\mathrm{NO}_{3}$ inside channel 2 for an equilibrated $\mathrm{NO}_{3} / \mathrm{N}_{2} \mathrm{O}_{5}$ mixture under zero flow conditions. The first order $\mathrm{N}_{2} \mathrm{O}_{5}$ uptake rate on the cavity's PFA walls, calculated by solving a set of coupled differential equations for the system, was found to be $0.042 \mathrm{~s}^{-1}$.

and $T_{2}, \sigma\left(T_{1}\right)$ and $\sigma\left(T_{2}\right)$, are $1.5 \%$ and $0.7 \%$ respectively. Note that changes to the PFA surface, in terms of its $\mathrm{NO}_{3}$ uptake properties, caused by aging or build-up of particulates during sampling, were investigated by performing the stopped flow experiment (detailed above) before take off and after landing each time the instrument has flown on the BAe 146 aircraft (an overview of the flights completed by the instrument to date is given in Sect. 6). Thus far, the measured $k_{\mathrm{NO}_{3} \text { loss }}$ rate coefficient has been, in each case, within the error of that quoted above, indicating any such effects to be negligible.

\subsubsection{Determination of the wall losses of $\mathrm{N}_{2} \mathrm{O}_{5}$ in channel 1}

This section details the determination of the transmission efficiency of $\mathrm{N}_{2} \mathrm{O}_{5}$ into channel 1, referred to herein as $T_{0} . T_{0}$ depends on several factors; direct wall losses of $\mathrm{N}_{2} \mathrm{O}_{5}$ in the inlet tubing, the dissociation efficiency of $\mathrm{N}_{2} \mathrm{O}_{5}$ in the preheater (see Sect. 3.2) and wall losses of the $\mathrm{NO}_{3}$ formed from the thermal dissociation of $\mathrm{N}_{2} \mathrm{O}_{5}$. Direct losses of $\mathrm{N}_{2} \mathrm{O}_{5}$ to the inlet surface were quantified by experimentally determining the rate constant for the reaction between $\mathrm{N}_{2} \mathrm{O}_{5}$ and

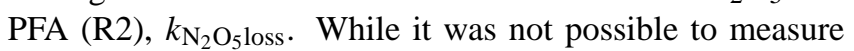
$k_{\mathrm{N}_{2} \mathrm{O}_{5} \text { loss }}$ directly, it could be inferred from the decay of $\mathrm{NO}_{3}$ when an equilibrated mixture of $\mathrm{NO}_{3}$ and $\mathrm{N}_{2} \mathrm{O}_{5}$ from the calibration source was allowed to decay under zero flow conditions (this experiment was conducted using channel 2 which is unheated). The results are illustrated in Fig. 6.

The observed first order decay of intracavity $\mathrm{NO}_{3}$ measured in channel 2 resulted from complex interplay between 
direct losses of $\mathrm{NO}_{3}$ to the walls together with re-partitioning of the $\mathrm{N}_{2} \mathrm{O}_{5} / \mathrm{NO}_{3}$ equilibrium due to losses of both $\mathrm{NO}_{3}$ and $\mathrm{N}_{2} \mathrm{O}_{5}$. The uptake of $\mathrm{N}_{2} \mathrm{O}_{5}$ to the PFA surface could be related to the measured $\mathrm{NO}_{3}$ decay using the reaction scheme $\mathrm{R} 2-\mathrm{R} 4$ which controls the rates of change of intracavity $\mathrm{NO}_{3}$

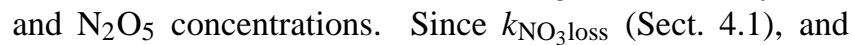
temperature were known, and $\mathrm{NO}_{2}$ concentrations could be monitored using channel 3 , this system of coupled differential equations describing the rates of reactions $\mathrm{R} 2-\mathrm{R} 4$ could be solved allowing retrieval of the uptake coefficient of $\mathrm{N}_{2} \mathrm{O}_{5}$ to PFA (R2).

$\begin{array}{lll}\mathrm{N}_{2} \mathrm{O}_{5} & \rightarrow \text { walls } & k_{\mathrm{N}_{2} \mathrm{O}_{5} \text { loss }} \\ \mathrm{N}_{2} \mathrm{O}_{5} & \rightarrow \mathrm{NO}_{3}+\mathrm{NO}_{2} & k_{\text {diss }} \\ \mathrm{NO}_{3} & \rightarrow \text { walls } & k_{\mathrm{NO}_{3} \text { loss }}\end{array}$

Note that the effect of reaction $\mathrm{R} 3$ is to buffer the $\mathrm{NO}_{3}$ lost to the walls, so the $\mathrm{NO}_{3}$ signal in channel 2 decayed rather slowly once the flow was stopped compared to that observed in channel 1 (cf. gradients of 0.27 and 0.052 in Figs. 5 and 6 respectively). The derived $\mathrm{N}_{2} \mathrm{O}_{5}$ to PFA wall loss coefficient was $k_{\mathrm{N}_{2} \mathrm{O}_{5} \text { loss }}=0.042 \mathrm{~s}^{-1} \pm 0.004 \mathrm{~s}^{-1}$ (this is an upper limit since $k_{\mathrm{NO}_{3} \text { loss }}$ was calculated at high temperature). Thus, given the short residence inside the PFA inlet before the sample enters the preheater where $\mathrm{N}_{2} \mathrm{O}_{5}$ is dissociated, the direct losses of $\mathrm{N}_{2} \mathrm{O}_{5}$ to the instrument walls are within the error of the $\mathrm{N}_{2} \mathrm{O}_{5}$ measurement at typical atmospheric concentrations, and could be neglected.

In summary we find that the rate of loss of $\mathrm{N}_{2} \mathrm{O}_{5}$ to the instruments' PFA walls is considerably slower than the rate of loss of $\mathrm{NO}_{3}$. For the flow conditions used, direct loss of $\mathrm{N}_{2} \mathrm{O}_{5}$ is negligible and the dominant factor determining $T_{0}$ is actually loss of $\mathrm{NO}_{3}$ following the dissociation of $\mathrm{N}_{2} \mathrm{O}_{5}$ in the instrument's preheater. As reported in Sect. 4.1, the first order coefficient for the loss of $\mathrm{NO}_{3}$ to PFA was found to be $0.27 \mathrm{~s}^{-1} \pm 0.02 \mathrm{~s}^{-1}$. Thus, based on a residence time between the preheater and detection cell of $250 \mathrm{~ms}$, the transmission efficiency of $\mathrm{N}_{2} \mathrm{O}_{5}$ into channel $1, T_{0}$, is calculated to be $93 \%$. However, we associate an error to $T_{0}, \sigma\left(T_{0}\right)$, of $6 \%$ in order to account for the possibility that the precise location of $\mathrm{N}_{2} \mathrm{O}_{5}$ dissociation within the preheater may vary with ambient temperature and $\mathrm{NO}_{2}$ concentrations (i.e. the $6 \%$ accounts for all possible locations).

\subsection{Other measurement uncertainties}

In addition to uncertainties associated with wall losses (Sects. 4.1.2 and 4.1.3), the total inaccuracy in measurements in both channels 1 and 2 depends on other factors. These are errors in the temperature and pressure corrected absorption cross sections used to fit the BBCEAS spectra, and the uncertainty in the length of the cell occupied by the sample relative to that occupied by the 100 SCCM flows of nitrogen used to flush each mirror surface. Each of these sources of error is considered below.

\subsubsection{Uncertainties in the $\mathrm{NO}_{3}$ absorption cross section}

The $\mathrm{NO}_{3}$ absorption cross sections are temperature dependent (Wangberg et al., 1997; Sander, 1986; Ravishankara and Mauldin, 1986; Yokelson et al., 1994) and therefore the cross sections used to fit $\mathrm{NO}_{3}$ 's absorption features in the BBCEAS spectra need to be appropriate for the conditions inside channels 1 and 2. At the temperatures encountered in channel 2 (i.e. typically below $298 \mathrm{~K}$ ) the $\mathrm{NO}_{3}$ cross section is calculated using the values determined by Yokelson et al. (1994). The resulting error associated with the $\mathrm{NO}_{3}$ cross section at these temperatures is $10 \%$. At the higher temperature in channel $1(353 \mathrm{~K})$, there are no wavelength resolved cross section measurements covering the $B^{2} E^{\prime}-X^{2} A_{2}^{\prime}$ band of $\mathrm{NO}_{3}$ available in the literature. However, two recent studies (Orphal et al., 2003; Osthoff et al., 2007) have indicated that the normalised band profile of this transition does not change its shape with temperature. Therefore, wavelength resolved cross sections for fitting spectra obtained in channel 1 were calculated by scaling the $\mathrm{NO}_{3}$ band profile determined by Yokelson et al. (1994) to the band's peak intensity at $662 \mathrm{~nm}$ measured at $353 \mathrm{~K}$ by Osthoff et al. (2007). The resulting accuracy of the high temperature $\mathrm{NO}_{3}$ cross sections used for the determination of intracavity $\mathrm{NO}_{3}$ concentrations in channel 1 is $13 \%$.

\subsubsection{Uncertainties in the $\mathrm{H}_{2} \mathrm{O}$ cross section}

This section describes the spectral fitting procedure developed to treat strong absorption by water vapour that spectrally overlaps with $\mathrm{NO}_{3}$ absorption in the $662 \mathrm{~nm}$ region and therefore must be accurately simulated in order to prevent errors from propagating to the retrieved $\mathrm{NO}_{3}$ concentrations. Calculating water vapour absorption cross sections for this purpose is complicated by well-documented problems associated with strongly absorbing $4 v+\delta$ polyad water lines that lead to near-complete attenuation of intracavity photons at line-centre, but remain unresolved due to the limited spectral resolution of the BBCEAS instrument (Ball and Jones, 2003; Langridge et al., 2008).

In previous field work (Langridge et al., 2008; Benton et al., 2010), the problem was overcome by simulating a range of "effective" water vapour cross-sections for the temperature, pressure and humidity conditions inside the detection cell. The simulated cross sections were then used to compile a lookup table from which the absorption cross sections appropriate for a given set of conditions could be recalled. However, while this method was accurate it was also computationally expensive and therefore slow. For the present work, a new iterative methodology was developed which gives the same results as the previous method but which is more efficient and can be implemented in almost real time. The steps involved in the new method are outlined below and in the flow diagram in Fig. 7. 


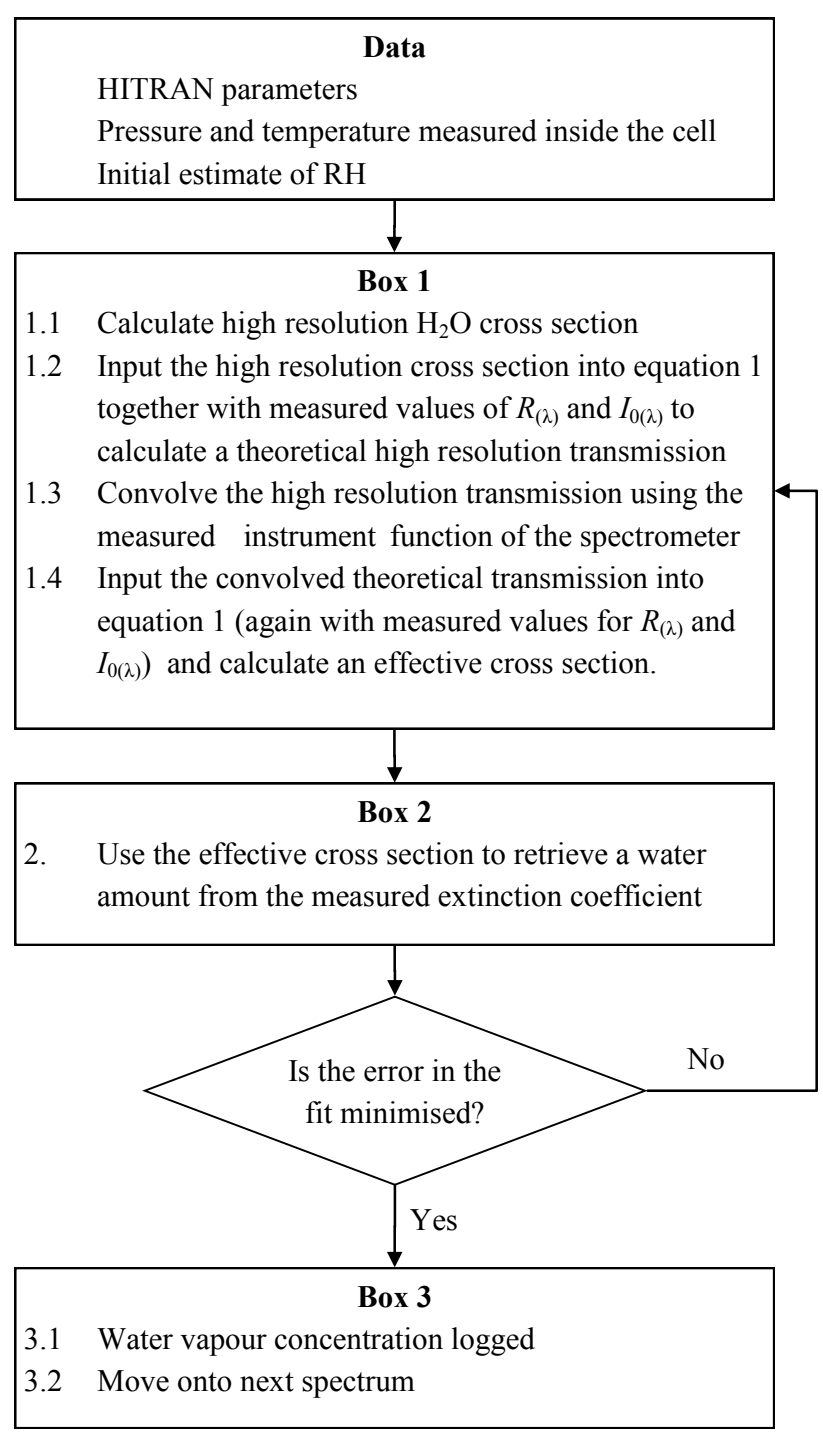

Fig. 7. Steps showing the algorithm for calculating intracavity water vapour concentrations in channels 1 and 2.

Firstly, a high resolution water vapour absorption cross section is calculated for a representative absolute humidity, accounting for self-broadening effects, and the pressure and temperature measured inside the cell using the line-by-line parameters in the Hitran database (Rothman et al., 2009) (step 1.1 in Fig. 7). Secondly, a theoretical cavity transmission spectrum, $I(\lambda)$, is determined from the measured values of $R(\lambda)$ and $I_{0}(\lambda)$ together with the calculated high resolution cross section using Eq. (1) (step 1.2). The theoretical $I(\lambda)$ is then convolved with the instrument function of the spectrometer (step 1.3), which is determined using essentially monochromatic emission lines from a neon lamp. The convolved $I_{0}(\lambda)$ is subsequently inputted into Eq. (1) allowing an effective cross section to be calculated, again using measured values of $R(\lambda)$ and $I_{0}(\lambda)$ (step 1.4), and used for retrieval of a first-estimate water concentration from the measured absorption coefficient using the aforementioned DOAS fitting algorithm (step 2). If the statistical uncertainty of the fit is not within the desired range then the retrieved water amount is used to calculate a new high resolution cross section and, following the steps outlined above, a second estimate water vapour concentration is determined. The cycle is repeated until the statistical uncertainty in the fitted water vapour absorption reaches a desired precision (i.e. better than $0.005 \%$ of absolute humidity). Usually this is achieved in less than five iterations. Using this method to remove the absorption of water vapour absorbance from each measured absorption spectrum effectively eliminates any effect of water vapour interference on $\mathrm{NO}_{3}$ absorption retrievals.

\subsubsection{Uncertainty in the length of the cell occupied by the sample}

In both channels 1 and 2, the length of the detection cell occupied by the sample is $85 \%$ of the distance separating the cavity mirrors. This was determined by comparison of ground based water vapour measurements in both cavities (under standard conditions and with the mirror sheath flow) to those reported by a commercial hygrometer (the measured absolute humidity was $1.4 \%$ ). Since the distance separating the inlet and outlet is $80 \%$ of the distance separating the cavity mirrors, this indicates that there is diffusion of sample gas into the purge volumes. However, given the possibility of this diffusion being slow relative to the rate at which $\mathrm{NO}_{3}$ is lost due to reaction with the instrument walls, we associate an error of $5 \%$ with the effective cavity length used to infer intracavity $\mathrm{NO}_{3}$ concentrations.

\subsection{Summary of $\mathrm{NO}_{3}$ measurement accuracy}

The uncertainties in the measurements of ambient $\mathrm{NO}_{3}$, which is performed using channel 2 , have been outlined above. These are the errors in; $T_{2}(0.7 \%)$; the temperature corrected cross section of $\mathrm{NO}_{3}(10 \%)$; and the assumed length of the cell occupied by the sample (5\%). Propagating these sources of errors brings the total error in the measurement of ambient $\mathrm{NO}_{3}$ to $11 \%$.

\subsection{Summary of $\mathrm{N}_{2} \mathrm{O}_{5}$ measurement accuracy}

The concentration of $\mathrm{N}_{2} \mathrm{O}_{5}$ is determined by subtracting the ambient $\mathrm{NO}_{3}$ measured in channel 2 from the concentration of the sum of ambient and dissociated $\mathrm{NO}_{3}$ measured in channel 1. The uncertainty in the $\mathrm{N}_{2} \mathrm{O}_{5}$ measurement, $\sigma\left(\mathrm{N}_{2} \mathrm{O}_{5}\right.$, is therefore dependent on the $\mathrm{NO}_{3} / \mathrm{N}_{2} \mathrm{O}_{5}$ ratio and is calculated for each individual measurement using Eq. (4), first proposed by Dube et al. (2006).

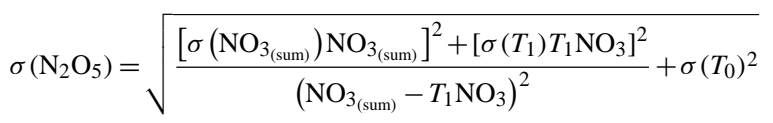


where: $\mathrm{NO}_{3}$ is the ambient $\mathrm{NO}_{3}$ concentration derived using channel 2 and $\mathrm{NO}_{3}$ (sum) is the concentration of $\mathrm{NO}_{3}$ in channel 1 which includes that from dissociation of $\mathrm{N}_{2} \mathrm{O}_{5}$. The terms in Eq. (4) are summarised in Table 2. The error in $\mathrm{NO}_{3 \text { (sum) }}, \sigma\left(\mathrm{NO}_{3 \text { (sum) }}\right)$, is due to uncertainties in the length of the cell occupied by the sample (5\%) and in the high temperature $\mathrm{NO}_{3}$ absorption cross sections $(13 \%)$. These two errors (detailed in Sects. 4.2.1 and 4.2.3) propagate to give an overall value for $\sigma\left(\mathrm{NO}_{3}\right.$ (sum) $)$ of $14 \%$. The errors in $T_{1}$ and $T_{0}, \sigma\left(T_{1}\right)$ and $\sigma\left(T_{1}\right)$, which are due to the inaccuracy of the determination of $k_{\mathrm{NO}_{3} \text { loss }}$ (detailed in Sect. 4.1.2) and the uncertainty in the location of $\mathrm{N}_{2} \mathrm{O}_{5}$ dissociation within the preheater (detailed in Sect. 4.1.3) are $1.5 \%$ and $6 \%$ respectively. Therefore, in accordance with Eq. (4), for ambient conditions where concentrations of $\mathrm{NO}_{3}$ and $\mathrm{N}_{2} \mathrm{O}_{5}$ are of comparable magnitude, the subtraction of ambient $\mathrm{NO}_{3}$ is the dominant source of error in the $\mathrm{N}_{2} \mathrm{O}_{5}$ measurement. Conversely, when $\mathrm{NO}_{3}$ concentrations are much lower than $\mathrm{N}_{2} \mathrm{O}_{5}$, as is more often the case in the atmosphere, the uncertainties associated with $\mathrm{N}_{2} \mathrm{O}_{5}$ sampling efficiency (i.e. transmission efficiency and other aforementioned uncertainties in channel 1) are dominant (Dube et al., 2006).

\section{Results}

\subsection{Determination of detection sensitivities}

The sensitivity of a BBCEAS measurement is determined by the smallest change in cavity throughput, $I_{\Delta \min }$, that can be detected resulting from molecular absorption inside the cavity. The corresponding minimum detectable absorption, $\alpha_{\min }$, is given as:

$\alpha_{\min }=\left(\frac{I_{0}}{I_{\Delta \min }}-1\right)\left(\frac{1-R}{d}\right)$

In order to achieve the required levels of sensitivity for in situ observations of weakly absorbing atmospheric species present at trace concentrations, BBCEAS detection performance can be enhanced in various ways. Firstly, higher reflectivity mirrors can be used to increase the cavity enhancement factor given by $1 /[1-R(\lambda)]$, as inferred by Eq. (1). However, resultant improvements in detection limits are offset by an increase in noise associated with fewer photons arriving at the detector per unit time due to the accompanying reduction in light intensity transmitted through the cavity which is roughly proportional to $1-R(\lambda)$. Sensitivity can also be improved by using a more luminous light source. This is because signal increases proportionally to the number of photons transmitted by the cavity, $N$, compared to the noise, which increases proportionally to $\sqrt{N}$ (when intracavity extinction is unchanged). For similar reasons, detection limits can also be improved by averaging successive measurements or by integrating the signal for longer periods on the spectrometers' CCD detector chip. Theoretically, averaging or integrating for longer times improves the signal/noise ratio by a factor of $\sqrt{t}$ where $t$ is the averaging or integration time ( $t$ is proportional to $N$ ). In practice, however, enhancements in detection performance gained by signal averaging or increased signal integration are often smaller than the expected factor of $\sqrt{t}$, owing to systematic, time dependent drifts in the instrument (Werle et al., 1993). Following Langridge et al. (2008), a laboratory experiment involving analysis of the Allan variance was conducted to determine the absolute detection limits of the present instrument Firstly, for each channel, a time series of absorption spectra was created using a long sequence of 45700 measurements of $I(\lambda)$ ( $2 \mathrm{~s}$ each) when the cavity was purged with nitrogen (total acquisition time $=12.7 \mathrm{~h}$ per cavity). A $120 \mathrm{~s}$ subset of the aforementioned data were then averaged to yield an $I_{0}(\lambda)$ spectrum, which was used with Eq. (1) to calculate a time series of absorption spectra spanning the $12.7 \mathrm{~h}$ measurement period. Each spectrum was analysed by least squares fitting the relevant absorption cross sections $\left(\mathrm{NO}_{3}\right.$ for channels 1 and 2 and $\mathrm{NO}_{2}$ for channel 3) together with a second order polynomial to account for any remaining unstructured absorption signal. This yielded a concentration time series for each channel. The wavelength bandwidths used for fitting the BBCEAS spectra were $433.4 \mathrm{~nm}-479.7 \mathrm{~nm}, 657.45 \mathrm{~nm}-$ 668.8 and $657.1 \mathrm{~nm}-668.1 \mathrm{~nm}$ for channels 1,2 and 3 respectively. The three time series were then used to generate three sets of time series of different averaging times, $t_{\mathrm{av}}$, and number of elements, $M$, by averaging successive measurements (e.g. a time series of $M=45700$ measurements for $t_{\mathrm{av}}=2 \mathrm{~s}$; a time series of $M=22850$ for $t_{\mathrm{av}}=4 \mathrm{~s}$ etc.). A maximum value of $3000 \mathrm{~s}$ was used for $t_{\mathrm{av}}$ so as to ensure a minimum of at least fifteen measurements in each time series. The Allan variance, $\sigma_{A}^{2}\left(t_{\mathrm{av}}\right)$, of each time series was then calculated using:

$\sigma_{A}^{2}\left(t_{\mathrm{av}}\right)=\frac{1}{2(M-1)} \sum_{i=1}^{M-1}\left[x_{i+1}\left(t_{\mathrm{av}}\right)-x_{i}\left(t_{\mathrm{av}}\right)\right]^{2}$

where: $x_{i}\left(t_{\mathrm{av}}\right)$ for $i=1$ to $i=M$ were the concentrations in the time series of averaging time, $t_{\mathrm{av}}$. The square root of the Allan variance, termed the Allan deviation, provides an indication of the instrument stability (Allan, 1966; Werle et al., 1993). The Allan deviation plots for each of the BBCEAS instrument's measurement channels are shown in Fig. 8.

The Allan plots show that white noise dominates concentration measurements by the BBCEAS instrument for averaging times shorter than $100 \mathrm{~s}$. In this regime, the magnitude of the drift across the whole time series is smaller than the difference between successive averaged concentration measurements, and accordingly the Allan deviations for all three channels decrease almost proportionally to the square root of the averaging time (gradients of $0.45,0.43$ and 0.45 for $\mathrm{NO}_{3}$ in channels $1, \mathrm{NO}_{3}$ in channel 2 and $\mathrm{NO}_{2}$ in channel 3 respectively). At longer averaging times, the difference between 
Table 2. The parameter required to solve Eq. (4), which is used to calculate the absolute error in the $\mathrm{N}_{2} \mathrm{O}_{5}$ measurement.

\begin{tabular}{|c|c|c|}
\hline Parameter & Description & $\begin{array}{l}\text { Associated } \\
\text { uncertainty }\end{array}$ \\
\hline $\mathrm{NO}_{3(\text { sum })}$ & $\begin{array}{l}\text { Concentration of } \mathrm{NO}_{3} \text { measured in channel } 1 \\
\text { (including dissociated } \mathrm{NO}_{3} \text { ) }\end{array}$ & $\sigma\left(\mathrm{NO}_{3(\text { sum })}\right)=14 \%$ \\
\hline$T_{1}$ & Transmission efficiency of ambient $\mathrm{NO}_{3}$ into channel 1 & $\sigma\left(T_{1}\right)=1.5 \%$ \\
\hline$T_{0}$ & Transmission efficiency of ambient $\mathrm{N}_{2} \mathrm{O}_{5}$ into channel 1 & $\sigma\left(T_{0}\right)=6 \%$ \\
\hline
\end{tabular}
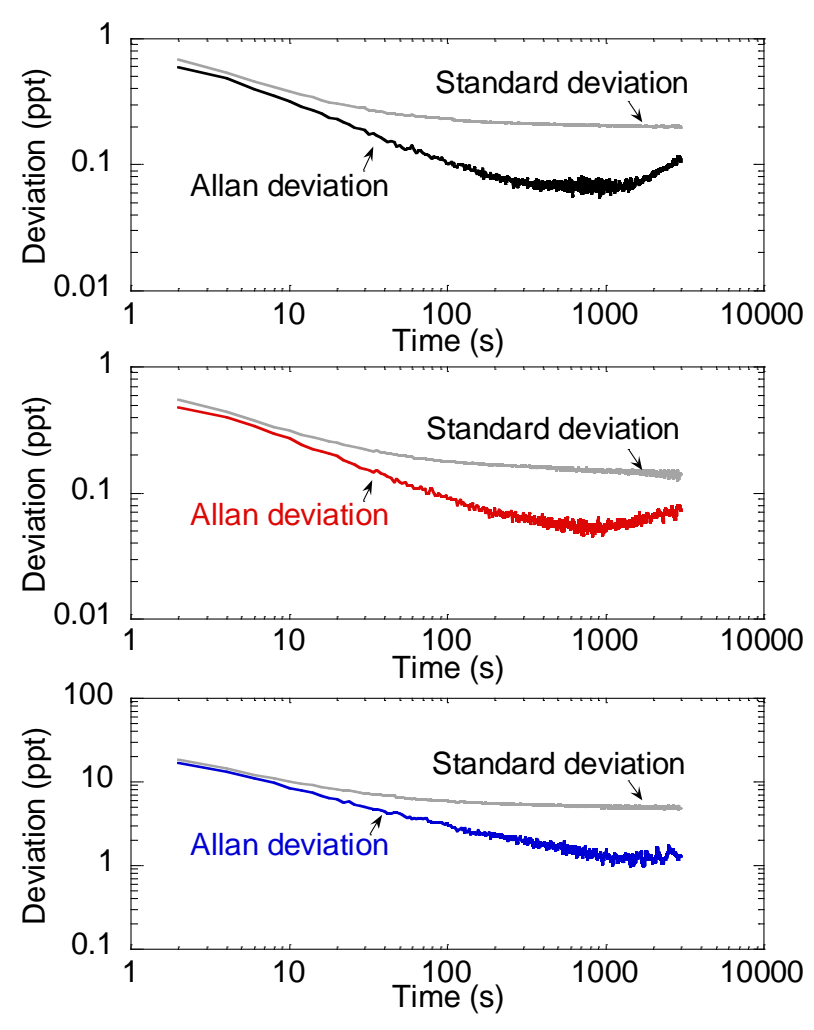

Fig. 8. Allan deviation plots (standard deviation also shown) for measurements of $\mathrm{NO}_{3}$ in the heated channel 1 (top panel), $\mathrm{NO}_{3}$ in channel 2 (middle panel) and $\mathrm{NO}_{2}$ in channel 3 (bottom panel). For averaging times of less than $100 \mathrm{~s}$ the Allan deviation decreases approximately as $\sqrt{t}$ (gradients of $0.45,0.43$ and 0.45 for top, middle and bottom plots respectively). The minima in the Allan plots indicate the optimum averaging times for maximum detection performance. The absolute detection performance using each channel is inferred from the standard deviation at the optimum averaging time, which offers a more conservative estimate than that suggested by the Allan deviation.

successive measurements is comparable to the drift across the entire time series, and thus increased averaging yields no benefit and is accompanied by increased Allan deviation. The detection limit in each channel is inferred from the $1 \sigma$ standard deviation of the samples of optimum averaging time, indicated by the minimum in the corresponding Allan plot
(Acker et al., 2006; Simpson, 2003; Schlosser et al., 2007). The $1 \sigma$ standard deviation, also plotted in Fig. 8, gives a more conservative estimate of detection performance than that suggested by the Allan deviation itself. The inferred $1 \sigma$ detection limits are $0.20 \mathrm{ppt} \mathrm{NO}_{3}$ in $850 \mathrm{~s}$ in channel 1 , $0.17 \mathrm{ppt}$ of $\mathrm{NO}_{3}$ in $830 \mathrm{~s}$ in channel 2 and 5 ppt of $\mathrm{NO}_{2}$ in $1748 \mathrm{~s}$ in channel 3 (at a pressure of 1 bar).

It is likely that for in situ measurements, the detection performance in each channel is worse than that quoted above. This is partly because of the shorter averaging times necessary to capture the small scale variability of the distributions of $\mathrm{N}_{2} \mathrm{O}_{5}, \mathrm{NO}_{3}$ and $\mathrm{NO}_{2}$ in the atmosphere while travelling at the aircraft's cruising speed of $\sim 100 \mathrm{~m} \mathrm{~s}^{-1}$. Furthermore the presence of aerosol particles and other absorbing gases can complicate the spectral fitting procedure, especially if the absorption cross sections cannot accurately be corrected for temperature, pressure or non-Beer-Lambert behaviour (Langridge et al., 2008). To better understand the in situ performance of channels 1 and 2 a further study was conducted. A time series of intracavity $\mathrm{NO}_{3}$ concentrations were calculated for both channels from sets of 2000 absorption spectra recorded at $1 \mathrm{~s}$ each during a daytime test flight. The typical photolysis lifetime of $\mathrm{NO}_{3}$ during the day is $\mathrm{J}\left(\mathrm{NO}_{3}\right) \approx 5 \mathrm{~s}$, and thus daytime $\mathrm{NO}_{3}$ and $\mathrm{N}_{2} \mathrm{O}_{5}$ concentrations are reasonably expected to be below the BBCEAS instrument's detection limits (a similar analysis could not be performed using measurements from channel 3 , as $\mathrm{NO}_{2}$ concentrations during the daytime were frequently above detection limits). However, both aerosols and water vapour were present and acted to attenuate light within the cavity during the measurements. The retrieved $\mathrm{NO}_{3}$ concentrations in channels 1 and 2, which are plotted as histograms in Fig. 9, were distributed about mean values of $-0.25 \mathrm{ppt}$ and $0.29 \mathrm{ppt}$ respectively. The $1 \sigma$ sample standard deviations of these distributions indicated detection limits for intracavity $\mathrm{NO}_{3}$ of $2.4 \mathrm{ppt}$ in channel 1 and $1.1 \mathrm{ppt}$ in channel 2 (at a pressure of $0.7 \mathrm{bar}$ ).

The detection limits determined from the in situ data are higher (i.e. less sensitive) than the optimum detection limits indicated by analysis of the Allan deviation in the laboratory. This is, in part, expected due to the much shorter integration times used in flight (cf. $1 \mathrm{~s}$ and $\sim 800 \mathrm{~s}$ ). However, extrapolating the Allan plots back to $1 \mathrm{~s}$ indicates $1 \mathrm{~s}$ laboratory detection limits (using the $1 \sigma$ standard deviation) for 

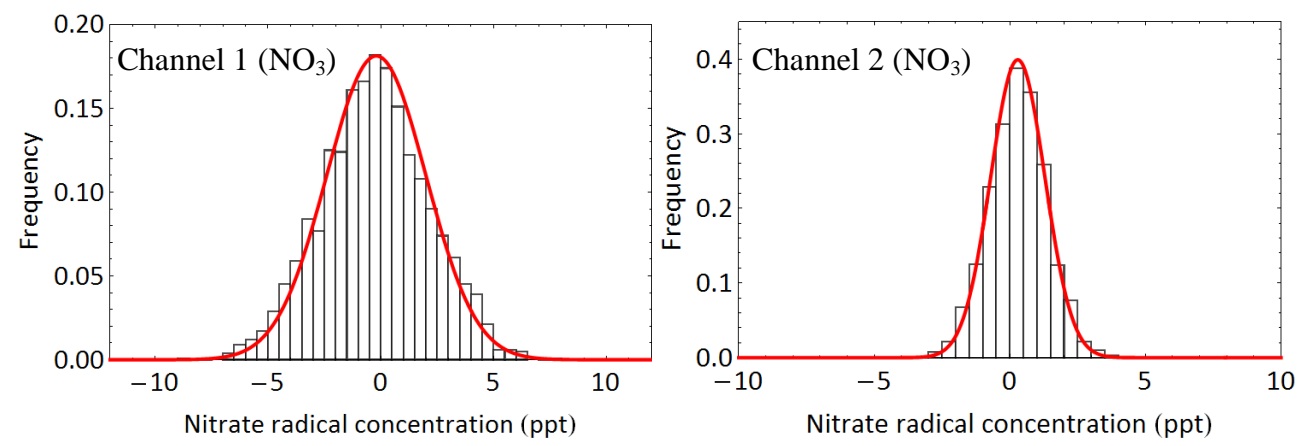

Fig. 9. Histograms showing the distribution of $\mathrm{NO}_{3}$ concentrations in channels 1 (left) and 2 (right) retrieved from 2000 absorption spectra recorded with $1 \mathrm{~s}$ integration time during a daytime flight when the $\mathrm{NO}_{3}$ and $\mathrm{N}_{2} \mathrm{O}_{5}$ concentrations were below the detection limits of the instrument. The $1 \sigma$ standard deviation of the distributions, which are used to infer the absolute detection performance, are $2.4 \mathrm{ppt}$ and $1.0 \mathrm{ppt}$ for channels 1 and 2 respectively (at a pressure of 0.7 bar).

channels 1 and 2 of $0.9 \mathrm{ppt}$ and $0.7 \mathrm{ppt}$ (at a pressure of $1 \mathrm{bar}$ ) respectively, which compares reasonably well with the in situ detection limit indicating only a small reduction in performance when the instrument is used on board the aircraft.

\subsection{Simultaneous airborne measurements of $\mathrm{NO}_{3}$, $\mathrm{N}_{2} \mathrm{O}_{5}$ and $\mathrm{NO}_{2}$}

To date the instrument has acquired over 120 hours of flighttime making airborne measurements of $\mathrm{NO}_{3}, \mathrm{~N}_{2} \mathrm{O}_{5}$ and $\mathrm{NO}_{2}$ concentrations. This includes 2 test flights in December 2009, eleven flights in July 2010, nine flights between August 2010 and September 2010 and eight flights in January 2011. The majority of the RONOCO flights (December 2009, July 2010 and January 2011) were conducted during the night, although some flights also included dawn or dusk in order to study the transitions between daytime and nighttime chemistry. The flights during August 2010 and September 2010 were associated with a different measurements campaign, SeptEx, and included seven daytime flights and a dawn and a dusk flight. All flights were based at East Midlands airport or Cranfield airport in the United Kingdom and sampled air over the UK, North Sea, English Channel and Irish Sea impacted by pollution from the UK and, occasionally, from continental Europe.

Figure 10 shows example BBCEAS spectra of our target species recorded on one night during the RONOCO campaign. The top panel in the figure shows a $1 \mathrm{~s}$ absorption measurement in channel 1 . Clearly visible are the overlapping absorptions of water vapour and $\mathrm{NO}_{3}$ (including, in this case, from thermally dissociated $\mathrm{N}_{2} \mathrm{O}_{5}$ ). The second and third panels in Fig. 10 show the same spectrum plotted in the top panel but decomposed into the individual absorption contributions from water vapour (fitted mixing ratio $=0.94 \%$ ) and $\mathrm{NO}_{3}(548 \pm 3 \mathrm{ppt})$ respectively. The forth panel shows a $1.2 \mathrm{~s}$ absorption measurement of ambient $\mathrm{NO}_{3}(80.0 \pm 1 \mathrm{ppt})$ in channel 2 , with the fitted water vapour absorption having been previously subtracted. The second from bottom and bottom panels respectively show measurements of $\mathrm{NO}_{2}$ $(3950 \pm 10 \mathrm{ppt})$ and $\mathrm{O}_{4}$ (inferred $\left.\left[\mathrm{O}_{2}\right]=21.0 \pm 2.6 \%\right)$ retrieved from an $8 \mathrm{~s}$ absorption spectrum in channel 3. Monitoring the absorption of $\mathrm{O}_{4}$ carries information about the pressure inside channel 3 during flight (which, in general, is of the order of that reported by instrument's pressure sensors, which were introduced in Sect. 3.2) and, at ground level, provides an independent verification of mirror reflectivity determination (Langridge et al., 2006). Note that the integration time used for each of the three channels was chosen to achieve the desired detection performance (see discussion on signal integration time and detection limits in Sect. 5.1).

As a more detailed example of airborne BBCEAS measurements, we now show concentration time series from the night-time flight on 20/21 July 2010 (mission B537). The flight track is shown in Fig. 11 with the relative concentrations of $\mathrm{NO}_{3}$ and $\mathrm{N}_{2} \mathrm{O}_{5}$ overlaid. The aircraft took off from East Midlands Airport, Leicestershire, UK (International Air Transport Association (IATA) airport code: EMA, coordinates: $52^{\circ} 49^{\prime} 52^{\prime \prime} \mathrm{N} 001^{\circ} 19^{\prime} 41^{\prime \prime} \mathrm{W}$ ) at 20:50 UTC before heading eastward toward the North Sea where several legs were completed at altitudes between $3400 \mathrm{~m}$ (aircraft transit) and $490 \mathrm{~m}$. The aircraft then flew along the Thames Estuary at an altitude of $640 \mathrm{~m}$ before making a missed approach into London Southend Airport, Essex, UK (IATA airport code: SEN, coordinates: $51^{\circ} 34^{\prime} 17^{\prime \prime} \mathrm{N} 000^{\circ} 41^{\prime} 44^{\prime \prime} \mathrm{E}$ ) at 22:10 UTC. Several further legs above the North Sea between $500 \mathrm{~m}$ and $2500 \mathrm{~m}$ were then completed (i.e. in and out of the boundary layer) before returning back to East Midlands Airport at approximately 01:10 UTC. Figure 12 shows the time series of $\mathrm{NO}_{2}, \mathrm{NO}_{3}$ and $\mathrm{N}_{2} \mathrm{O}_{5}$ concentrations for the majority of the flight, averaged over $1 \mathrm{~s}, 1.2 \mathrm{~s}$ and $8 \mathrm{~s} \mathrm{respec}-$ tively (altitude is also shown). During the flight, concentrations of $\mathrm{NO}_{3}$ and $\mathrm{N}_{2} \mathrm{O}_{5}$ varied from below the instrument detection limit ( $\sim 2 \mathrm{ppt})$ up to around $200 \mathrm{ppt}$ and $600 \mathrm{ppt}$ respectively. Concentrations of $\mathrm{NO}_{2}$ ranged from below $50 \mathrm{ppt}$ up to around $12 \mathrm{ppb}$ in the most polluted regions. The time 

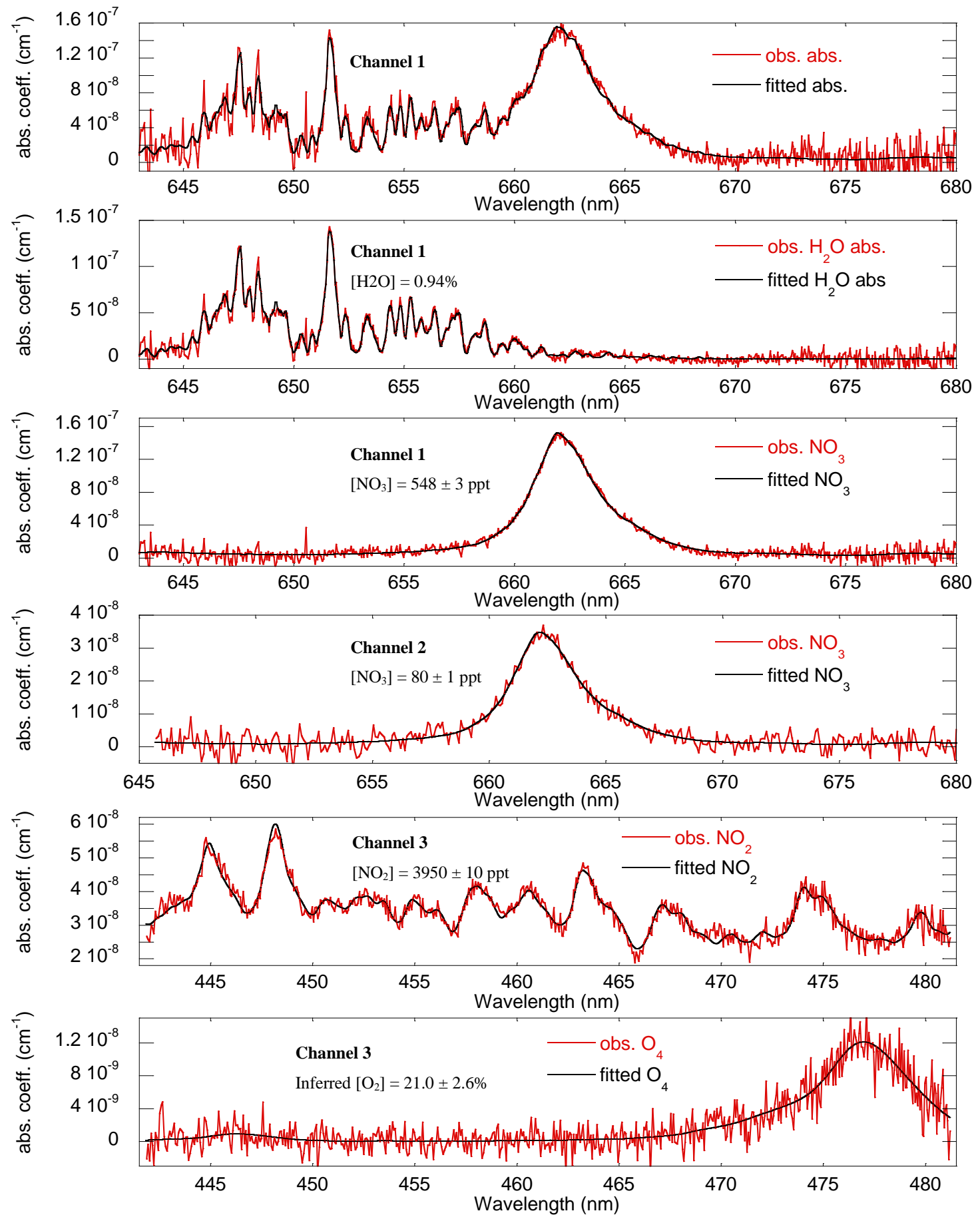

Fig. 10. Examples of retrieved and fitted absorption spectra of several different species measured during the flight on 20/21 July 2010. See text for details.

series (Fig. 12) illustrate that elevated concentrations of all three species were observed when the aircraft was flying at lower altitudes, most notably at 21:30 UTC, 22:10 UTC, 23:00 UTC and 00:15 UTC. The peak $\mathrm{NO}_{2}$ concentration was observed during the missed approach into Southend airport at 21:10 UTC. However, while simultaneous peaks were also observed in the $\mathrm{N}_{2} \mathrm{O}_{5}$ and $\mathrm{NO}_{3}$ measurements they were not as pronounced as the large $\mathrm{NO}_{2}$ maximum, most likely due to titration of $\mathrm{NO}_{3}$ (and thus $\mathrm{N}_{2} \mathrm{O}_{5}$ too) by surface emissions of $\mathrm{NO}$ by the reaction:

$\mathrm{NO}+\mathrm{NO}_{3} \rightarrow 2 \mathrm{NO}_{2}$ 


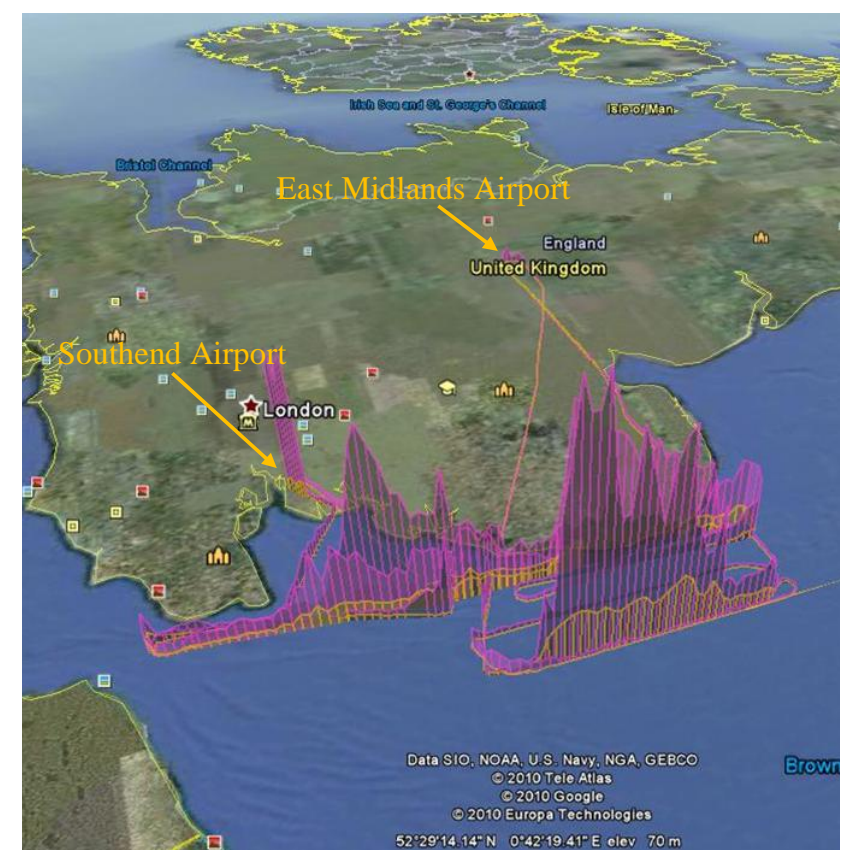

Fig. 11. Flight track of the FAAM BAe 146-301 during the night of 20/21 July 2010. The relative concentrations (see Fig. 12 for time series) of $\mathrm{NO}_{3}$ (orange) and $\mathrm{N}_{2} \mathrm{O}_{5}$ (purple) are shown along the flight track.

The maxima observed in the $\mathrm{NO}_{3}$ and $\mathrm{N}_{2} \mathrm{O}_{5}$ time series, which are clearly visible in the flight track shown in Fig. 10, occurred at around 00:15 when the aircraft was undertaking a southward run at $500 \mathrm{~m}$, parallel to the coast of East Anglia, England, UK. Here the aircraft was flying through a fairly stagnant air mass containing pollution from several plumes, including the London plume, which was slowly drifting northward over the English Channel and North Sea. Earlier in the flight, first at 21:30 UTC over the Thames Estuary at $490 \mathrm{~m}$ and then at 23:00 UTC over the coat of East Anglia at $1020 \mathrm{~m}$, the same air mass had been sampled and had contained similarly elevated concentrations of the measured species, as visible in the time series. More in-depth analysis of the data from this and other flights, including modelling calculations of the nighttime chemistry and analysis of ancillary measurements of aerosol mass loading and speciation, will be presented in subsequent publications.

\subsection{Comparison of in-flight measurements of $\mathrm{NO}_{2}$ by the BBCEAS instrument and a chemiluminescence detector}

Included in the suite of instruments on board the FAAM BAe-146 aircraft is a chemiluminescence (CL) detector which, during the RONOCO campaigns, provided a second measurement of $\mathrm{NO}_{2}$ concentrations to compare with the BBCEAS data. The PFA sample inlets of both these instruments (wall losses of $\mathrm{NO}_{2}$ to PFA were measured in the lab- oratory to be negligible) are located on the port side of the aircraft and are less than $10 \mathrm{~m}$ apart. The CL detector utilises a photolytic converter (blue-light LED, centred at $395 \mathrm{~nm}$ ) to minimise $\mathrm{NO}_{\mathrm{y}}$ interferences which are associated with other CL techniques using molybdenum converters (Ryerson et al., 2000; Pollack et al., 2011), and undergoes frequent in-flight calibrations. A recent intercomparison study showed a similar CL detector to deliver highly reliable $\mathrm{NO}_{2}$ measurements (Fuchs et al., 2010) that agreed well with those using other techniques (CRDS and laser induced fluorescence). The left panel in Fig. 13 shows the time series of $\mathrm{NO}_{2}$ measured by the CL detector and the BBCEAS instrument for the flight of 20/21 July 2010. The CL and BBCEAS data were obtained with $1 \mathrm{~s}$ and $0.4 \mathrm{~s}$ integration times respectively, but in constructing Fig. 13 both datasets have been averaged over $30 \mathrm{~s}$ intervals. Figure 13 shows that the two instruments report very similar $\mathrm{NO}_{2}$ concentrations, and the variability in the $\mathrm{NO}_{2}$ time series is extremely well matched. The right panel of Fig. 13 shows a correlation plot of the CL and BBCEAS data from this flight: there is a strong correlation between the data $\left(R^{2}=0.996\right)$ and a linear best fit yields a gradient of nearly unity (1.02) and small intercept $(-10 \mathrm{ppt})$. The excellent agreement with the established CL method demonstrates the high reliability of the BBCEAS performance in airborne deployments, and the validity of the phase-shift methodology used to infer the mirror reflectivity before/during/after each flight.

\section{Conclusions}

A new broadband cavity enhanced absorption spectrometer has been constructed and flown on the UK's FAAM atmospheric research aircraft during four deployments between December 2009 and January 2011. It is (to our knowledge) the first BBCEAS instrument designed for airborne use and the first to have three separate optical channels. The instrument was designed to enable in situ measurements of $\mathrm{NO}_{3}$, $\mathrm{N}_{2} \mathrm{O}_{5}, \mathrm{H}_{2} \mathrm{O}$ and $\mathrm{NO}_{2}$ during the Role of Nighttime Chemistry in Controlling the Oxidising Capacity of the Atmosphere "RONOCO" campaign.

This paper describes novel developments in BBCEAS instrumentation and analysis techniques. Firstly, a refined method for determination of the cavity mirror reflectivities using a phase-shift technique was presented. The new method reduced the time required for measurements compared to previous similar methods, and was implemented using a simpler experiment setup that was well-suited for in situ deployment. Furthermore, when used to measure the cavity mirror reflectivities in the present BBCEAS instrument, excellent agreement was observed between subsequently retrieved $\mathrm{NO}_{2}$ concentrations and those reported by a chemiluminescence detector (Sect. 5.3). Secondly, a computationally efficient method for calculating water vapour absorption cross sections at the resolution of the BBCEAS instrument 

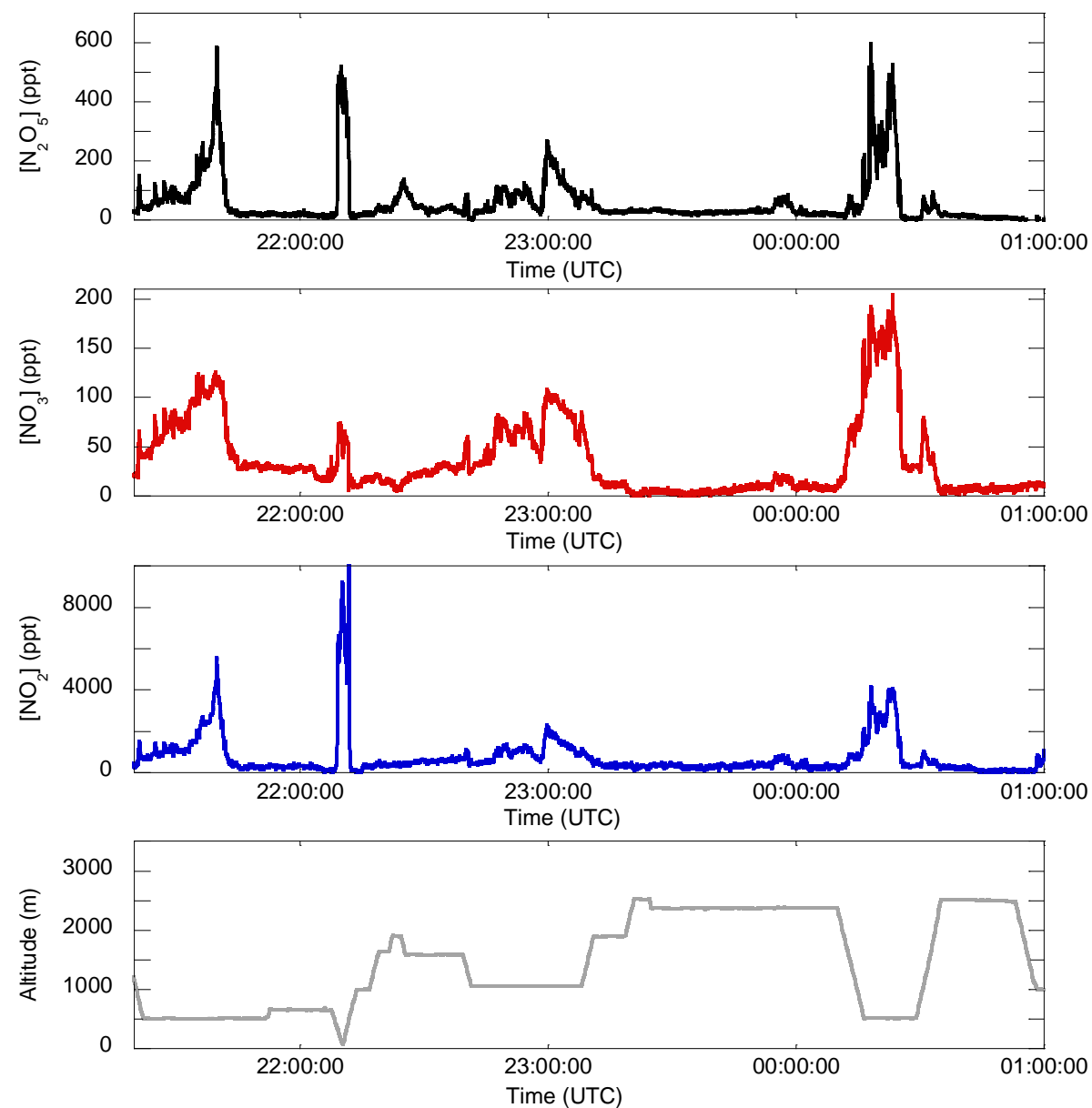

Fig. 12. Time series of $\mathrm{N}_{2} \mathrm{O}_{5}, \mathrm{NO}_{3}$ and $\mathrm{NO}_{2}$ concentrations and altitude (top to bottom) for the nighttime flight on 20/21 July 2010. See text for description of the flight.
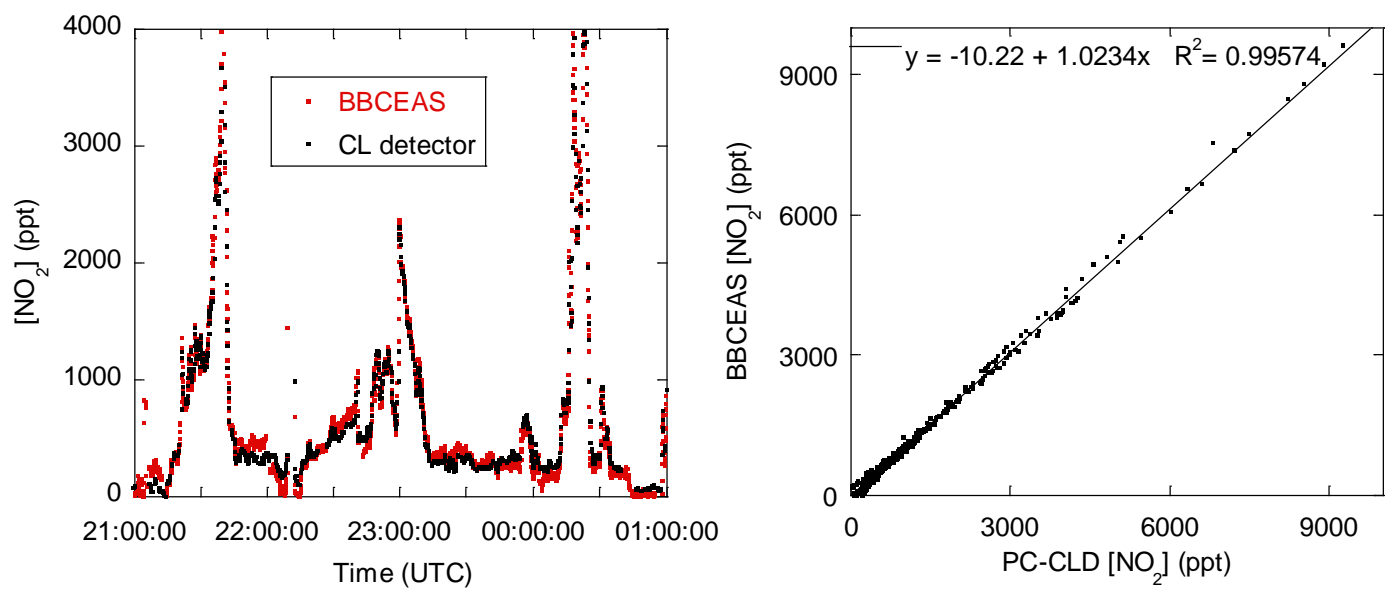

Fig. 13. The left panel shows a time series of simultaneous ambient $\mathrm{NO}_{2}$ measurements made by the BBCEAS instrument (red) and a chemiluminescence detector (black). The measurements by the two instruments were each averaged over $30 \mathrm{~s}$. The correlation between the two data sets is plotted in the right hand panel and indicates excellent agreement $\left(R^{2}=0.99\right.$, gradient $=1.02$, intercept $\left.=-10 \mathrm{ppt}\right)$. 
was presented. This approach prevented errors associated with poorly fitted water absorption structure from interfering with $\mathrm{NO}_{3}$ concentrations measured in the $662 \mathrm{~nm}$ region. The paper also presented the first example of simultaneous airborne measurements of $\mathrm{N}_{2} \mathrm{O}_{5}, \mathrm{NO}_{3}$ and $\mathrm{NO}_{2}$ outside of North America. Example measurements were shown from a flight on the night of 20/21 July 2010, which was the most polluted day encountered during the RONOCO flights. These data illustrate the ability of the BBCEAS instrument to make rapid measurements of atmospheric trace gases and thereby capture their spatial and temporal variability, which is essential for understanding the small-scale variability of reactive trace species in the atmosphere, particularly in the present context the $\mathrm{NO}_{3}$ chemistry (night-time processing of volatile organic compounds and night-time deposition of $\mathrm{NO}_{\mathrm{x}}$ ) occurring preferentially at the interfaces between pollution plumes and the background atmosphere (Jones et al., 2005) . The reliability of the BBCEAS instrument and methodology were demonstrated by a comparison of in-flight $\mathrm{NO}_{2}$ measurements to those reported by a $\mathrm{CL}$ detector (agreement between the two instruments within $2.3 \%$ for $\mathrm{NO}_{2}$ concentrations covering the dynamic range $0-16 \mathrm{ppbv})$.

Acknowledgements. This work was performed within the RONOCO consortium supported by the Natural Environmental Research Council (NERC) (University of Cambridge grant award reference RG50086 MAAG/606, University of Leicester grant award reference NE/F006761/1). It was completed in collaboration with the Facility for Airborne Atmospheric Measurements, Avalon Aero and DirectFlight. Mark J. S. Daniels acknowledges NERC for a PhD studentship. We acknowledge Bill Dubé and Steve Brown (both at NOAA Earth System Research Laboratory, R/CSD7, 325 Broadway, Boulder, CO 80305, USA) for their advice on the design of the $\mathrm{N}_{2} \mathrm{O}_{5}$ source. Finally, we thank the reviewers for their interest in the paper and their helpful comments.

Edited by: M. D. Andrés Hernóndez

\section{References}

Acker, K., Moller, D., Wieprecht, W., Meixner, F. X., Bohn, B., Gilge, S., Plass-Dulmer, C., and Berresheim, H.: Strong daytime production of $\mathrm{OH}$ from $\mathrm{HNO}_{2}$ at a rural mountain site, Geophys. Res. Lett., 33, L02809, doi:10.1029/2005g1024643, 2006.

Allan, D. W.: Statistics of atomic frequency standards, Proceedings of the IEEE, 54, 221-230, 1966.

Andrés-Hernández, M. D., Stone, D., Brookes, D. M., Commane, R., Reeves, C. E., Huntrieser, H., Heard, D. E., Monks, P. S., Burrows, J. P., Schlager, H., Kartal, D., Evans, M. J., Floquet, C. F. A., Ingham, T., Methven, J., and Parker, A. E.: Peroxy radical partitioning during the AMMA radical intercomparison exercise, Atmos. Chem. Phys., 10, 10621-10638, doi:10.5194/acp10-10621-2010, 2010.

Ball, S. M. and Jones, R. L.: Broad-band cavity ring-down spectroscopy, Chem. Rev., 103, 5239-5262, doi:10.1021/cr020523k, 2003.
Ball, S. M., Langridge, J. M., and Jones, R. L.: Broadband cavity enhanced absorption spectroscopy using light emitting diodes, Chem. Phys. Lett., 398, 68-74, doi:10.1016/j.cplett.2004.08.144, 2004.

Ball, S. M and Jones, R. L.: Broadband Cavity Ring-Down Spectroscopy, in: Cavity Ring-Down Spectroscopy: Techniques and Applications, Blackwell Publishing Ltd, UK, 57-88, 2009

Ball, S. M., Hollingsworth, A. M., Humbles, J., Leblanc, C., Potin, P., and McFiggans, G.: Spectroscopic studies of molecular iodine emitted into the gas phase by seaweed, Atmos. Chem. Phys., 10, 6237-6254, doi:10.5194/acp-10-6237-2010, 2010.

Benton, A. K., Langridge, J. M., Ball, S. M., Bloss, W. J., Dall'Osto, M., Nemitz, E., Harrison, R. M., and Jones, R. L.: Night-time chemistry above London: measurements of $\mathrm{NO}_{3}$ and $\mathrm{N}_{2} \mathrm{O}_{5}$ from the BT Tower, Atmos. Chem. Phys., 10, 9781-9795, doi:10.5194/acp-10-9781-2010, 2010.

Brown, S. S., Stark, H., Ciciora, S. J., McLaughlin, R. J., and Ravishankara, A. R.: Simultaneous in situ detection of atmospheric $\mathrm{NO}_{3}$ and $\mathrm{N}_{2} \mathrm{O}_{5}$ via cavity ring-down spectroscopy, Review of Scientific Instruments, 73, 3291-3301, doi:10.1063/1.1499214, 2002a.

Brown, S. S., Stark, H., and Ravishankara, A. R.: Cavity ring-down spectroscopy for atmospheric trace gas detection: application to the nitrate radical $\left(\mathrm{NO}_{3}\right)$, Appl. Phys. B-Lasers O., 75, 173-182, doi:10.1007/s00340-002-0980-y, 2002b.

Brown, S. S.: Absorption Spectroscopy in High-Finesse Cavities for Atmospheric Studies, Chem. Rev., 103, 5219-5238, doi:10.1021/cr020645c, 2003.

Capes, G., Murphy, J. G., Reeves, C. E., McQuaid, J. B., Hamilton, J. F., Hopkins, J. R., Crosier, J., Williams, P. I., and Coe, H.: Secondary organic aerosol from biogenic VOCs over West Africa during AMMA, Atmos. Chem. Phys., 9, 3841-3850, doi:10.5194/acp-9-3841-2009, 2009.

Chang, W. L., Bhave, P. V., Brown, S. S., Riemer, N., Stutz, J., and Dabdub, D.: Heterogeneous atmospheric chemistry, ambient measurements, and model calculations of $\mathrm{N}_{2} \mathrm{O}_{5}$ : A review, Aerosol Science and Technology, 45, 655-685, 2011.

Chen, J. and Venables, D. S.: A broadband optical cavity spectrometer for measuring weak near-ultraviolet absorption spectra of gases, Atmos. Meas. Tech., 4, 425-436, doi:10.5194/amt-4-4252011, 2011.

Crowley, J. N., Schuster, G., Pouvesle, N., Parchatka, U., Fischer, H., Bonn, B., Bingemer, H., and Lelieveld, J.: Nocturnal nitrogen oxides at a rural mountain-site in south-western Germany, Atmos. Chem. Phys., 10, 2795-2812, doi:10.5194/acp-10-27952010, 2010.

Dube, W. P., Brown, S. S., Osthoff, H. D., Nunley, M. R., Ciciora, S. J., Paris, M. W., McLaughlin, R. J., and Ravishankara, A. R.: Aircraft instrument for simultaneous, in situ measurement of $\mathrm{NO}_{3}$ and $\mathrm{N}_{2} \mathrm{O}_{5}$ via pulsed cavity ring-down spectroscopy, Rev. Sci. Instrum., 77, 034101, doi:10.1063/1.2176058, 2006.

Engeln, R., Berden, G., Peeters, R., and Meijer, G.: Cavity enhanced absorption and cavity enhanced magnetic rotation spectroscopy, Rev. Sci. Instrum., 69, 3763-3769, doi:10.1063/1.1149176, 1998.

Fiedler, S. E., Hese, A., and Ruth, A. A.: Incoherent broad-band cavity-enhanced absorption spectroscopy, Chem. Phys. Lett., 371, 284-294, doi:10.1016/s0009-2614(03)00263-x, 2003.

Fuchs, H., Dube, W. P., Ciciora, S. J., and Brown, S. S.: Deter- 
mination of Inlet Transmission and Conversion Efficiencies for in Situ Measurements of the Nocturnal Nitrogen Oxides, $\mathrm{NO}_{3}$, $\mathrm{N}_{2} \mathrm{O}_{5}$ and $\mathrm{NO}_{2}$, via Pulsed Cavity Ring-Down Spectroscopy, Anal. Chem., 80, 6010-6017, doi:10.1021/ac8007253, 2008.

Fuchs, H., Ball, S. M., Bohn, B., Brauers, T., Cohen, R. C., Dorn, H.-P., Dub, W. P., Fry, J. L., Hseler, R., Heitmann, U., Jones, R. L., Kleffmann, J., Mentel, T. F., Msgen, P., Rohrer, F., Rollins, A. W., Ruth, A. A., Kiendler-Scharr, A., Schlosser, E., Shillings, A. J. L., Tillmann, R., Varma, R. M., Venables, D. S., Villena Tapia, G., Wahner, A., Wegener, R., Wooldridge, P. J., and Brown, S. S.: Intercomparison of measurements of $\mathrm{NO}_{2}$ concentrations in the atmosphere simulation chamber SAPHIR during the $\mathrm{NO}_{3}$ Comp campaign, Atmos. Meas. Tech., 3, 21-37, doi:10.5194/amt-3-212010, 2010.

Hallock, A. J., Berman, E. S. F., and Zare, R. N.: Direct Monitoring of Absorption in Solution by Cavity Ring-Down Spectroscopy, Anal. Chem., 74, 1741-1743, doi:10.1021/ac011103i, 2002.

Johnson, B. T., Christopher, S., Haywood, J. M., Osborne, S. R., McFarlane, S., Hsu, C., Salustro, C., and Kahn, R.: Measurements of aerosol properties from aircraft, satellite and groundbased remote sensing: a case-study from the Dust and Biomassburning Experiment (DABEX), Q. J. Roy. Meteorol. Soc., 135, 922-934, doi:10.1002/qj.420, 2009.

Jones, R. L., Ball, S. M., and Shallcross, D. E.: Small scale structure in the atmosphere: implications for chemical composition and observational methods, Faraday Discuss., 130, 165-179, 2005.

Langridge, J. M., Ball, S. M., and Jones, R. L.: A compact broadband cavity enhanced absorption spectrometer for detection of atmospheric $\mathrm{NO}_{2}$ using light emitting diodes, Analyst, 131, 916922, doi:10.1039/b605636a, 2006.

Langridge, J. M., Ball, S. M., Shillings, A. J. L., and Jones, R. L.: A broadband absorption spectrometer using light emitting diodes for ultrasensitive, in situ trace gas detection, Rev. Sci. Instrume., 79, 123110, doi:10.1063/1.3046282, 2008.

Langridge, J. M., Gustafsson, R. J., Griffiths, P. T., Cox, R. A., Lambert, R. M., and Jones, R. L.: Solar driven nitrous acid formation on building material surfaces containing titanium dioxide: A concern for air quality in urban areas?, Atmos. Environ., 43, 5128-5131, doi:10.1016/j.atmosenv.2009.06.046, 2009.

Lewis, A. C., Evans, M. J., Methven, J., Watson, N., Lee, J. D., Hopkins, J. R., Purvis, R. M., Arnold, S. R., McQuaid, J. B., Whalley, L. K., Pilling, M. J., Heard, D. E., Monks, P. S., Parker, A. E., Reeves, C. E., Oram, D. E., Mills, G., Bandy, B. J., Stewart, D., Coe, H., Williams, P., and Crosier, J.: Chemical composition observed over the mid-Atlantic and the detection of pollution signatures far from source regions, J. Geophys. Res., 112, D10S39, doi:10.1029/2006jd007584, 2007.

Mazurenka, M., Orr-Ewing, A. J., Peverall, R., and Ritchie, G. A. D.: Cavity ring-down and cavity enhanced spectroscopy using diode lasers, Annual Reports Section "C" (Phys. Chem.), 101, 100-142, 2005.

O'Keefe, A. and Deacon, D. A. G.: Cavity ring-down optical spectrometer for absorption measurements using pulsed laser sources, Rev. Sci. Instrum., 59, 2544-2551, doi:10.1063/1.1139895, 1988.

Orphal, J., Fellows, C. E., and Flaud, P. M.: The visible absorption spectrum of $\mathrm{NO}_{3}$ measured by high-resolution Fourier transform spectroscopy, J. Geophys. Res., 108, 4077, doi:10.1029/2002jd002489, 2003.
Osthoff, H. D., Pilling, M. J., Ravishankara, A. R., and Brown, S. S.: Temperature dependence of the $\mathrm{NO}_{3}$ absorption cross-section above $298 \mathrm{~K}$ and determination of the equilibrium constant for $\mathrm{NO}_{3}+\mathrm{NO}_{2} \leftrightarrow \mathrm{N}_{2} \mathrm{O}_{5}$ at atmospherically relevant conditions, Phys. Chem. Chem. Phys., 9, 5785-5793, 2007.

Pfister, G. G., Emmons, L. K., Hess, P. G., Honrath, R., Lamarque, J. F., Val Martin, M., Owen, R. C., Avery, M. A., Browell, E. V., Holloway, J. S., Nedelec, P., Purvis, R., Ryerson, T. B., Sachse, G. W., and Schlager, H.: Ozone production from the 2004 North American boreal fires, J. Geophys. Res., 111, D24S07, doi:10.1029/2006jd007695, 2006.

Platt, U. and Stutz, J.: Differential Absorption Spectroscopy, in: Differential Optical Absorption Spectroscopy, Physics of Earth and Space Environments, Springer Berlin Heidelberg, 135-174, 2008.

Pollack, I., Lerner, B., and Ryerson, T.: Evaluation of ultraviolet light-emitting diodes for detection of atmospheric $\mathrm{NO}_{2}$ by photolysis - chemiluminescence, J. Atmos. Chem., 1-15, doi:10.1007/s10874-011-9184-3, 2011.

Ravishankara, A. R. and Mauldin, R. L.: Temperature-Dependence of the $\mathrm{NO}_{3}$ Cross-Section in the 662-nm Region, J. Geophys. Res.-Atmos., 91, 8709-8712, 1986.

Rothman, L. S., Gordon, I. E., Barbe, A., Benner, D. C., Bernath, P. F., Birk, M., Boudon, V., Brown, L. R., Campargue, A., Champion, J. P., Chance, K., Coudert, L. H., Dana, V., Devi, V. M., Fally, S., Flaud, J. M., Gamache, R. R., Goldman, A., Jacquemart, D., Kleiner, I., Lacome, N., Lafferty, W. J., Mandin, J. Y., Massie, S. T., Mikhailenko, S. N., Miller, C. E., Moazzen-Ahmadi, N., Naumenko, O. V., Nikitin, A. V., Orphal, J., Perevalov, V. I., Perrin, A., Predoi-Cross, A., Rinsland, C. P., Rotger, M., Šimeková, M., Smith, M. A. H., Sung, K., Tashkun, S. A., Tennyson, J., Toth, R. A., Vandaele, A. C., and Vander Auwera, J.: The HITRAN 2008 molecular spectroscopic database, J. Quant. Spectrosc. Ra., 110, 533-572, 2009.

Ryerson, T. B., Williams, E. J., and Fehsenfeld, F. C.: An efficient photolysis system for fast-response $\mathrm{NO}_{2}$ measurements, J. Geophys. Res.-Atmos., 105, 26447-26461, 2000.

Sander, S. P.: Temperature dependence of the nitrogen trioxide absorption spectrum, J. Phys. Chem.-US, 90, 4135-4142, doi:10.1021/j100408a060, 1986.

Scherer, J. J., Paul, J. B., O’Keefe, A., and Saykally, R. J.: Cavity Ringdown Laser Absorption Spectroscopy:? History, Development, and Application to Pulsed Molecular Beams, Chem. Rev., 97, 25-52, doi:10.1021/cr930048d, 1997.

Schlosser, E., Bohn, B., Brauers, T., Dorn, H.-P., Fuchs, H., Häseler, R., Hofzumahaus, A., Holland, F., Rohrer, F., Rupp, L., Siese, M., Tillmann, R., and Wahner, A.: Intercomparison of Two Hydroxyl Radical Measurement Techniques at the Atmosphere Simulation Chamber SAPHIR, J. Atmos. Chem., 56, 187-205, doi:10.1007/s10874-006-9049-3, 2007.

Simpson, W. R.: Continuous wave cavity ring-down spectroscopy applied to in situ detection of dinitrogen pentoxide $\left(\mathrm{N}_{2} \mathrm{O}_{5}\right)$, Rev. Sci. Instrum., 74, 3442-3452, doi:10.1063/1.1578705, 2003.

Thalman, R. and Volkamer, R.: Inherent calibration of a blue LED-CE-DOAS instrument to measure iodine oxide, glyoxal, methyl glyoxal, nitrogen dioxide, water vapour and aerosol extinction in open cavity mode, Atmos. Meas. Tech., 3, 1797-1814, doi:10.5194/amt-3-1797-2010, 2010.

Varma, R. M., Venables, D. S., Ruth, A. A., Heitmann, U., 
Schlosser, E., and Dixneuf, S.: Long optical cavities for openpath monitoring of atmospheric trace gases and aerosol extinction, Appl. Opt., 48, B159-B171, 2009.

Wada, R., Beames, J., and Orr-Ewing, A.: Measurement of IO radical concentrations in the marine boundary layer using a cavity ring-down spectrometer, J. Atmos. Chem., 58, 69-87, doi:10.1007/s10874-007-9080-z, 2007.

Wagner, N. L., Dubé, W. P., Washenfelder, R. A., Young, C. J., Pollack, I. B., Ryerson, T. B., and Brown, S. S.: Diode laser-based cavity ring-down instrument for $\mathrm{NO}_{3}, \mathrm{~N}_{2} \mathrm{O}_{5}, \mathrm{NO}$, $\mathrm{NO}_{2}$ and $\mathrm{O}_{3}$ from aircraft, Atmos. Meas. Tech., 4, 1227-1240, doi:10.5194/amt-4-1227-2011, 2011.

Wang, L. M. and Zhang, J. S.: Detection of nitrous acid by cavity ring down spectroscopy, Environ. Sci. Technol., 34, 4221-4227, 2000 .
Wangberg, I., Etzkorn, T., Barnes, I., Platt, U., and Becker, K. H.: Absolute determination of the temperature behavior of the $\mathrm{NO}_{2}$ $+\mathrm{NO}_{3}+(\mathrm{M}) \leftrightarrow \mathrm{N}_{2} \mathrm{O}_{5}+(\mathrm{M})$ equilibrium, J. Phys. Chem. A, 101, 9694-9698, 1997.

Werle, P., Mücke, R., and Slemr, F.: The limits of signal averaging in atmospheric trace-gas monitoring by tunable diode-laser absorption spectroscopy (TDLAS), Appl. Phys. B-Lasers O., 57, 131-139, doi:10.1007/bf00425997, 1993.

$\mathrm{Xu}$, S., Sha, G., and Xie, J.: Cavity ring-down spectroscopy in the liquid phase, Rev. Sci. Instrum., 73, 255-258, doi:10.1063/1.1430729, 2002.

Yokelson, R. J., Burkholder, J. B., Fox, R. W., Talukdar, R. K., and Ravishankara, A. R.: Temperature Dependence of the $\mathrm{NO}_{3}$ Absorption Spectrum, J. Phys. Chem., 98, 13144-13150, doi:10.1021/j100101a009, 1994. 